\title{
Estudio teológico-místico del título cristológico "Hijo de Dios" en "De los Nombres de Cristo" de Fray Luis de León
}

(Cóntinuación) *

\author{
$4^{\circ}$. NACIMIENTO: CRISTO NACE EN LA EUCARISTIA.
}

\section{Introducción}

Al comenzar el cuarto nacimiento, Juliano continúa su disertación-diálogo con esta premisa, que consta de dos partes y una conclusión.

1) La primera parte presenta el hecho del cuarto nacimiento, y lo une con el nacimiento anterior. Juliano razona de esta manera:

"Mas, ¡cuán no comprensibles son las maravillas de Dios! El que nació resucitando... y el que vive ${ }^{1}$ para siempre, dichoso en resplandores y en luz ${ }^{2}$, halló manera para tornar a nacer cada día encubierto y disimulado ${ }^{3}$ en las manos del sacerdote en la Hostia".

Y añade una delicada reflexión, que nos hace ver la finura del alma místi$c a$ de Fray Luis. Nos hace entrever que Cristo siente contento, alegría y regocijo en nacer, "como saboreándose (dice) en nacer este solo Hijo... que tantas veces y por tantas maneras es Hijo" ${ }^{4}$, y siempre en bien de los hombres.

* La primera parte de este estudio: Primer nacimiento: Cristo "nace" del Padre en cuanto Dios.- Segundo nacimiento: Cristo "nació" de la Virgen María en cuanto hombre.- Tercer nacimiento: Cristo "nació" en su Resurreción, se publicó en "Estudio Agustiniano", vol. XXVIIIFasc. I-1993, pp. 3-56.

1. "...y el que vive" = alusión al tercer nacimiento: "Cristo nació en su Resurrección"; v. nota 46 y el texto correspondiente de dicho nacimiento en la primera parte del presente estudio.

2. "...en resplandores y en luz" = de nuevo, alusión al tercer nacimiento: v. notas 15.36 y texto correspondiente, $y$, en general, todo el contexto del nacimiento anterior.

3. "encubierto y disimulado" = exteriormente oculto, bajo las apariencias de pan y de vino. Recuérdense los contrastes anotados: $2^{\circ}$ nacimiento $=$ texto y notas: 7.9.13.37 y 44 . Es decir, es el mismo Cristo de los otros nacimientos, por pequeño que aparezca exteriormente.

4. "tantas veces... es Hijo" = es decir, los tres nacimientos estudiados en la primera parte de este trabajo: 1) Nacimiento del Padre; 2) Nacimiento de María Virgen; 3) En la Resurrección; 
2) La segunda parte de la premisa es una prueba teológica de la primera y presupone el hecho del misterio eucarístico en sí mismo. Juliano argumenta así:

"Porque (dice) el estar Cristo en su Sacramento, y el comenzar a ser cuerpo suyo lo que antes era pan ${ }^{5}$, y sin dejar el cielo, y sin mudar su lugar ${ }^{6}$, comenzar de nuevo a ser allí adonde antes no era, convirtiendo toda la substancia del pan en su santísima carne ${ }^{7}$, mostrándose la carne como si fuese pan $^{8}$, vestida de accidentes ${ }^{9}$, es como un nacer alli ${ }^{10}$, en cierta manera".

3) La conclusión, finalmente, incluye también dos partes:

En la "primera parte", resume simplemente el hecho global y presenta la razón teológica de este cuarto nacimiento, como una consecuencia lógica de las dos premisas anteriores. Juliano expone la conclusión de esta manera:

"Así que ${ }^{11}$...Cristo nace allí, porque comienza a ser de nuevo allí cuando el sacerdote consagra" 12 .

En la "segunda parte", ofrece una doble explicación:

En primer lugar, hace una velada referencia al segundo nacimiento -Cristo, nacido de la Virgen en cuanto hombre-, cuando dice: "Y parece que la Hostia es como el vientre ${ }^{13}$ adonde se celebra este nacimiento".

En segundo lugar, aduce la razón teológica de este nacimiento, cuando afirma que "las palabras son como la virtud ${ }^{14}$ que allí se pone".

y en el quinto nacimiento: En el alma del justo, que explicará después, porque todos se hallan contenidos místicamente en la Eucaristía.

5. "lo que antes era pan" = alusión a la "causa efectiva" que hace posible este cuarto nacimiento: "la consagración, que cambia el pan en el Cuerpo de Cristo": Denz. 884; DSch. 1652.

6. "y sin mudar de lugar" = Cristo, omnipotente como Dios; como hombre, "al modo de los espíritus", pero realmente presente donde quiera que se realiza el misterio eucarístico: Denz. 874; DSch. 1636.

7. "convirtiendo toda la substancia de pan en su santísima carne" = alude al modo cómo se realiza esta presencia: "cambio de la substancia de pan en el Cuerpo de Cristo"; v. n. 5.- Sobre esto, v. Pablo SeXto, Profesión de fe, n. 25.

8. "como si fuese pan", es decir, la apariencia es de pan común; en realidad, en cambio, es el cuerpo de Cristo. dos.

9. "vestida de accidentes" = cantidad etc., es decir, lo único que pueden apreciar los senti-

10. "es como un nacer alli" = un nuevo nacer, es decir, en este cuarto nacimiento: la Eucaristía: Denz. 874s; DSch. 1636s.

11. "Así que" = por este motivo; es ilativo y demostrativo al mismo tiempo, que indica el nexo de lo que sigue con lo anterior: v. $1^{\mathrm{er}}$. nacimiento: nota $7 ; 2^{\circ}$. nacimiento, nota 69 , en la primera parte de este estudio.

12. "cuando el sacerdote consagra" = en el mismo momento que consagra, porque en este momento se da la "razón efectiva" de la presencia de Cristo en la Eucaristía: la consagración, es decir, las palabras del sacerdote.

13. "parece que la Hostia es como el vientre = alude al segundo nacimiento de Cristo: en el seno de María Virgen.

14. "las palabras son como la virtud" = es decir, el poder o la fuerza de Dios. 
Y por último, las palabras finales ofrecen una aclaración filosófico-teológica, hasta donde el entendimiento humano puede llegar, al tratar de explicar, de algún modo, el misterio eucarístico, que, en la mente de Fray Luis, conlleva un cuarto nacimiento. El razonamiento que aduce Juliano es de cuño netamente escolástico. Para él la razón explicativa de que "toda la materia y toda la forma del pan... en Él se convierta", es la virtud de Dios".

\subsection{El nacimiento de Cristo en la Eucaristía, resumen de los otros nacimientos}

Juliano da un paso más en su exposición. Hasta aquí ha explicado cómo el comenzar Cristo en la Eucaristía, por la virtud ${ }^{15}$ que Dios confiere a las palabras del sacerdote, que convierten el pan en el cuerpo de Cristo, es un nuevo nacimiento. Ahora afirma que este cuarto nacimiento es un resumen de todos los otros nacimientos.

Comienza el razonamiento como lo hizo anteriormente, es decir, con una premisa previa de orientación general, antes de demostrar por qué este nacimiento incluye, en cierto modo, todos los demás nacimientos. El razonamiento de Juliano es muy claro:

Este cuarto nacimiento no solamente es un nacimiento como los demás, sino que "es como una suma de sus otros nacimientos, en que se hace retrato ${ }^{16}$ de ellos y los dibuja y los pinta" ${ }^{17}$.

\subsection{Exposición teológico-mística}

Sentada esta premisa, Juliano comienza su paciente labor para demostrar que, efectivamente, los demás nacimientos se hallan, de algún modo, contenidos en la Eucaristía. El párrafo es de una gran densidad, y es preciso fijar detenidamente la atención para apreciar la riqueza teológico-mística que contiene.

En la exposición, Juliano altera en alguna ocasión el orden en que ha presentado los tres nacimientos precedentes ${ }^{18}$. No obstante, seguiré en mi exposición el orden que ha seguido Fray Luis hasta aquí, orden que, lógica-

15. "por la virtud" = v. la nota anterior.

16. "se hace retrato" = se hace resumen, compendio de los otros nacimientos.

17. "los pinta" = los hace presentes. Es una idea cara a Fray Luis $=$ v. $1^{\mathrm{er}}$. nacimiento: 1.1 .2 : La imagen del pintor.

18. Juliano cita primero el nacimiento tercero que el segundo: BAC 725; AP 468. 
mente, he seguido también en la primera parte del presente estudio, al estudiar los tres primeros nacimientos. Esto hará más fácil su lectura.

\subsubsection{Presentación}

Juliano comienza a probar detalladamente que, efectivamente, en este cuarto nacimiento -la Eucaristía - se hallan contenidos todos los otros nacimientos de Cristo, estudiados hasta ahora. El dialogante razona de esta manera:

1. Primer nacimiento: "El Hijo nace de la divinidad como Palabra, que la dice el entendimiento divino" 19 .

$1^{\text {a }}$. Aquí... comienza a ser de nuevo en la Hostia por virtud de la palabra que el sacerdote pronuncia" 20.

2. Segundo nacimiento: Cristo "nació de la Virgen...

a) bienaventurado en la parte más alta del alma ${ }^{21}$ - y pasible con el cuerpo, y sujeto a dolores y muerte" ${ }^{22}$;

b) "en lo secreto ${ }^{23}$ era la verdadera riqueza, - y en lo que de fuera se veía era un pobre y humilde".

$2^{\mathrm{a}}$. Aquí, a) "por de fuera ${ }^{24}$ parece un pequeño y despreciado, - y en lo escondido ${ }^{25}$ es todos los tesoros del cielo; b) según lo que parece, puede ser partido y quebrado y comido, - mas según lo que encubre, no puede ni el mal ni el dolor llegar a Él".

3. Tercer nacimiento: "En la Resurrección (Cristo) nació del sepulcro con su carne verdadera, - pero hecha a las condiciones del alma y vestida de sus maneras de gloria" ${ }^{26}$.

19. "Palabra que la dice el entendimiento divino" = Alude al modo cómo es engendrado el Hijo por el Padre: v. 1er. nacimiento, en la primera parte del presente estudio: 1.1; 1.1.1; 1.1.2; 1.2 , donde se explica esta idea con amplitud.

20. Recuérdese la nota 14: La virtud, el poder infinito de Dios es la única explicación posible del misterio eucarístico. Esto se ha de tener siempre en cuenta para este cuarto nacimiento: La Eucaristía.

21. Recuérdense los múltiples contrastes, anotados anteriormente, por ejemplo en el segundo nacimiento, notas: 7.9.13.14 y el texto correspondiente.

22. La misma idea de la nota anterior.

23. "en lo secreto" = interiormente; v. $3^{\text {er }}$ nacimiento: La Resurrección, nota 33a y el texto correspondiente, donde se expone la misma idea.

24. "por de fuera" = exteriormente; $v$. la nota anterior.

25. "en lo escondido" = interiormente, en la realidad; v. la nota 21.

26. "carne verdadera, pero hecha a las condiciones del alma", "vestida de sus maneras de gloria" = es decir, agilidad, sutileza, impasibilidad etc; v. $3^{\text {er }}$ nacimiento: La Resurrección, notas 7.8.13.15 etc., y prácticamente todo el contexto del nacimiento anterior. 
$3^{a}$. Aquí"...consagrado en la Hostia, está... su cuerpo en realidad de ver$d_{a d}{ }^{27}$, - mas como si fuera espíritu, todo en la Hostia toda, y en cada parte de ella todo también" 28 .

\subsubsection{Sintesis}

Juliano hace luego una mini-síntesis de la argumentación anterior y, al mismo tiempo, amplía algunos conceptos y presenta otros nuevos:

Primer nacimiento: Cuando (el Hijo) nació de Dios, "se forjaron en Él, como en sus ideas ${ }^{29}$, las criaturas".

Segundo nacimiento: Cuando nació en la carne, "la recibió para limpiar y librar al hombre" 30 .

Tercer nacimiento: Cuando nació en el sepulcro, "nos sacó a la vida a todos juntamente consigo" 31 .

En resumen, concluye:

1. En todos sus nacimientos "siempre hubo algún respeto a nuestro bien y provecho" 32 .

$1^{a}$. En este cuarto nacimiento de la consagración de su cuerpo "tuvo respeto al mismo bien". Y ofrece la explicación: "porque puso en él, no solamente su Cuerpo verdadero, sino también el místico de sus miembros" 33 .

1. En los demás nacimientos "nos ayuntó siempre a sí mismo" 34.

27. "en realidad de verdad" = realmente es el cuerpo de Cristo.

28. "todo en la Hostia toda y en cada parte" = alude al modo como está Cristo en la Hostia, de manera semejante a como está el alma en el cuerpo, por su simplicidad y espiritualidad, vitalizando y sensibilizando todo el cuerpo y cada una de sus partes.

29. "se forjaron en Él, como en sus ideas" = en el Verbo están "todas las razones, del ser y de la vida de las cosas creadas"; v. $1^{\text {er }}$ nacimiento: 1.1.2; 1.2 y notas 29.66.- Sobre esto v. S. GoNZALEZ, La preocupación arriana en la predicación de san Agustín: 1.- Tratados sobre el Evangelio y 1 a Epístola de san Juan. 2.- Enarraciones sobre los Salmos. 3.- Sermones al pueblo. "Estudio Agustiniano". Valladolid 1989, pp. 322 y 341. 5 o.

30. "recibió la carne para limpiar al hombre" = v. $2^{\circ}$ nacimiento, notas: 3.7 .45 .67 , y $3^{\text {er }}$ nacimiento, notas: 59.61 .64 y el texto correspondiente, donde se puede apreciar hasta dónde Cristo se hizo una sola cosa con los hombres para redimirlos.

31. "nos sacó a la vida..." = v. el $3^{\text {er }}$ nacimiento: notas 64 y 65 .

32. "siempre hubo algún respeto..." = siempre miró, pensó etc., en nuestro bien: v. $1{ }^{\mathrm{er}}$ nacimiento, notas 66.67; $2^{\circ}$ nacimiento, 2.4: Reflexiones teológico-místicas, y 2.10: Resumen del segundo nacimiento: Cristo, nacido en cuanto hombre; $3^{\text {er }}$ nacimiento, notas: 59.60 .67 y el texto correspondiente.

33. "Puso en Él... el Cuerpo... místico": v. $3^{\text {er }}$ nacimiento, 3.6: El tercer nacimiento aventaja al segundo. Contrastes.

34. "nos ayuntó siempre a sí mismo": v. la nota 32. 
$1^{\mathrm{a}}$. También en éste: a) "quiso contenernos en sí, b) y... que, encerrados en él y pasando a nuestras entrañas su carne, nos comunicásemos unos con otros, para que por Él viniésemos a ser todos, por unión de espíritu, un cuerpo y un alma" 35 .

\subsubsection{Prueba escriturística. Sentido teológico-místico}

Fray Luis acude, finalmente, como es su costumbre, a la Escritura para confirmar lo expuesto anteriormente.

Juliano presenta, antes que todo, una introducción de la prueba que va a exponer. La introducción tiene dos partes:

La primera parte es simplemente expositiva del hecho:

"Por lo cual (dice), el pan caliente ${ }^{36}$, que estaba de continuo en el templo y delante ${ }^{37}$ del Arca de Dios, que tuvo figura de este Pan divinísimo, le llama Pan de faces $^{38}$ la Sagrada Escritura, para enseñar que este Pan verdadero tiene faces ${ }^{39}$ innumerables".

Fray Luis piensa aquí, sin duda, en el sentido teológico-místico, que la tradición constante de la Iglesia ha dado al maná histórico, el cual, aunque era el mismo para todos, se acomodaba a las necesidades de cada uno y satisfacía todos los gustos. Unicamente no gustaba a quienes preferían otra cosa, por tener el gusto extragado: aquellos que se acordaban de los "pepinos, melones, puerros y cebollas y ajos" ${ }^{40}$ de Egipto, durante los años de la esclavitud.

35. "viniésemos a ser, por unión de espíritu, un cuerpo y un alma" = Fray Luis presenta aquí una mini-síntesis de la "teología del Cuerpo místico": El Espíritu de Jesús es el que realiza la "unión mística" entre nosotros y con Cristo, haciendo de nosotros un cuerpo místico y una sola alma, el alma única de Cristo, que permanentemente vitaliza, de modo misterioso, pero real, todo el organismo místico.

36. "pan caliente"= pan elaborado o cocido: ver Núm 11,8 .

37. "que estaba... delante": en realidad, el maná se conservaba en la misma arca.

38. "Pan de faces" = puede significar: a) que el maná se presentaba a modo de escarcha, alargado, como en fibras; b) que tenía diversos sabores, como Juliano explica a continuación.

39. "tiene faces innumerables" = aspectos, sabores, virtudes innumerables, en conformidad con la disposición, preparación o necesidad personal de quien lo come.

40. man, maná: Num 11, 4.6; Ex 16, 31.35. Poco importa el origen material del maná: a) Sustancia dulce y pegajosa que producían ciertos insectos al chupar la sabia de arbustos de tamarisco; b) o una capa de rocío, que, al evaporarse, se presentaba en forma fibrosa, a manera de escarcha (Sal 147, 16; Si 43, 19; Ex 16, 13-14); c) gomorresina de ciertos arbustos del desierto etc.: (v. Num 11, 6-8). En cualquier caso, Fray Luis quiere demostrar, al recordar este hecho, la providencia especial de Dios sobre el pueblo elegido en el desierto. La tradición cristiana ha visto siempre en el maná una figura de la Eucaristía, alimento espiritual de la Iglesia en su peregrinar hacia el Señor (v. Jn 6, 26-58). 


\subsubsection{Prueba teológico-mística}

La segunda parte de la introducción es una prueba teológico-mística del hecho mismo del maná:

Juliano explica que la palabra faces quiere decir que este Pan eucarístico "contiene en sí a sus miembros y que, como en la divinidad abraza en sí, por eminente manera, a todas las criaturas ${ }^{41}$, así en la humanidad y en este Sacramento santísimo, donde se encierra, encierra consigo ${ }^{42}$ a los suyos".

Precisa que los demás nacimientos acontecieron por nuestro bien y que Dios "hizo en éste lo que en los demás nacimientos, que fue nuestro bien, que consiste en andar siempre juntos con Él" ${ }^{43}$.

En otras palabras:

Cristo realiza en este cuarto nacimiento - La Eucaristía- lo que había anhelado $^{44}$ realizar en los demás nacimientos.

En el curso del diálogo, Juliano aduce estas pruebas de sentido teológico profundamente místico:

a) "Porque aquí, hecho mantenimiento nuestro, y ...juntando con nuestra carne la suya, si la halla dispuesta: 1) mantiene al alma 2) y purifica la carne 3), y apaga el fuego vicioso, 4) y pone a cuchillo ${ }^{45}$ a nuestra vejez, 5) y arranca de raíces el mal, 6) y nos comunica su ser 7) y (nos comunica) su vida, 8) y, comiéndole nosotros, nos come Él a nosotros 9) y nos viste de sus cualidades, 10) y ${ }^{46}$, finalmente, cuasi nos convierte en sí mismo".

41. "en la divinidad abraza en sí... a todas las criaturas" = es decir, como "causa", como "razón de ser", como "forma de todas las formas": v. la nota 30; v. también $1^{\text {er }}$ nacimiento: Cristo nace del Padre en cuanto Dios, notas: 29.43.66.72.73; $2^{\circ}$ nacimiento: Cristo nació de María Virgen en cuanto hombre, notas: $45.46 .67 ; 3^{\text {er }}$ nacimiento: Cristo nació en su Resurrección, notas: 59.60.61.64.65 y el texto correspondiente de todas estas notas, en la primera parte del presente estudio.

42. "encierra consigo a los suyos": v. la nota anterior.

43. "nuestro bien... consiste en andar siempre juntos con Él" = Recuérdese que, en la mente de Fray Luis, todos los modos de nacer o de ser Hijo Cristo, fueron para nuestro bien: v. la nota 4 y texto correspondiente. Recíprocamente, por lo tanto, nuestro bien se cifra en vivir unidos siempre a Cristo, unión vivencial que este $4^{\circ}$ nacimiento: La Eucaristía, compendia y realiza.

44. "lo que había anhelado realizar": Recuérdense las palabras de Cristo: "Con gran deseo he deseado comer esta Pascua con vosotros": Lc 22,16; v. $2^{\circ}$ nacimiento, 2.4: Reflexiones teológico-místicas.

45. "pone a cuchillo" = mete a cuchillo: P. Félix García, BAC 726 nota 139, es decir: rejuvenece totalmente nuestra vejez.

46. " $\mathrm{y}+\mathrm{y} . . . "=$ repite nueve veces la " $\mathrm{y}$ " copulativa (polisíndeton): $\mathrm{v}$. passim la aplicación de esta figura retórica en los nacimientos anteriores, que este cuarto nacimiento resume. 
Juliano continúa y redondea su argumentación con mayor precisión todavía, para explicar el sentido místico completo de este cuarto nacimiento la Eucaristía:

"Y trae ${ }^{47}$ aquí (dice) a fruto y a espiga lo que sembró en los demás nacimientos primeros" 48 .

$\mathrm{Y}$, como es su costumbre, aduce una prueba de la Escritura, brevísima, tomada ahora del libro de los Salmos:

Hizo memorial de sus maravillas el Señor misericordioso y piadoso; y dio a los que le temen manjar ${ }^{49}$.

Este cuarto nacimiento, por lo tanto, se realiza especialmente para aquellos que temen al Señor, como recordación y compendio de los otros nacimientos.

Juliano prosigue su exposición y añade otras pruebas. Las presento en su totalidad, separadas, para apreciar más claramente su precisión teológica y su belleza literaria:

b) Porque "en este manjar, que lo es propiamente para los que lo temen, recapituló todas sus grandezas pasadas: que en Él hizo ejemplo clarísimo de su infinito poder, de su saber infinito, y de su misericordia, y de su amor con los hombres".

En una palabra, Juliano concluye que esto fue un "ejemplo jamás oído ni visto".

c) Esto explica que "no contento ni de haber nacido hombre entre ellos, ni de haber muerto por ponerlos en vida, ni de haber renacido para subirlos a gloria, ni de estar junto siempre a la diestra del Padre, para su defensa y amparo; para su regalo y consuelo, y para que le tengan siempre, no solamente presente, sino que le puedan abrazar consigo mismos, y ponerlo en su pecho, y encerrarlo dentro de su corazón, y como chuparle ${ }^{50}$ sus bienes y atraerlos a sí:

1) Se les presenta en manjar y, como si dijésemos, les nace en figura de trigo, 2) para que así le coman y traguen y traspasen ${ }^{51}$ a sus entrañas, adon-

47. "y trae...a" = torna, cambia en: P. Félix García, BAC 726, nota 140.

48. "Y trae... a" = cambia en: la frase, en su brevedad, resume la doctrina completa del Cuerpo místico.

49. BAC 726; AP 470.

50. "chuparle": Fray Luis utiliza las palabras más populares para dar más viveza a la frase. Hoy esta expresión la empleamos en sentido peyorativo: P. Félix García, BAC 726, nota 142.

51. "coman y traguen, y traspasen": Fray Luis emplea estos tres verbos, de significado asimilativo progresivo. 
de, encerrado y ceñido ${ }^{52}$, con el calor del espíritu ${ }^{53}$, fructifique y nazca en ellos de otra manera".

Juliano añade, finalmente, que ésta es la quinta y la última manera de nacer, es decir: En el alma del justo, que será el tema del quinto nacimiento.

\subsection{Lirismo místico-literario}

Fácilmente se habrá podido apreciar cómo el dialogante ha rendondeado y perfilado, aún más, los argumentos anteriores en estos últimos párrafos, y cómo ha empleado para ello una habilidad literaria insuperable, pero sin disminuir un ápice la profundidad teológica anterior.

Fray Luis emplea, en efecto, una ténica admirable, y, al mismo tiempo, intenta sugerir el significado delicadamente místico de las palabras y de todo el contexto en su exposición. Con el procedimiento literario empleado, logra fijar más y más la atención del lector.

Para conseguir estos efectos, emplea, progresivamente, los tiempos: a) presente de indicativo, b) pretérito, $\mathrm{c}$ ) participio pasado, d) infinitivo "a modo de" enclítico, e) presente de indicativo nuevamente, $\mathrm{y}$, finalmente, f) el presente de subjuntivo.

En la exposición-diálogo, Juliano emplea los siguientes verbos:

a) En presente de indicativo, con sus complementos respectivos ${ }^{54}$, cuando dice que Cristo, hecho mantenimiento nuestro: mantiene, purifica, apaga, pone, arranca, comunica, éste con doble complemento: "su ser y su vida"; come, viste, convierte, con un gerundio intermedio, comiéndole, que presenta la idea de todos estos verbos en abstracto, como realizada en presente, lento, lentísimo, y que alarga aún más la fuerza presencial de los verbos aducidos en tiempo presente.

b) En tiempo pretérito de indicativo aduce los verbos: hizo, dio, tomados del ejemplo escriturístico; recapituló, con un complemento: "todas las cosas pasadas", de carácter general; hizo ejemplo, con cuatro complementos cir-

52. "adonde, encerrado y ceñido" = ¿alusión velada a las palabras de Jesús: "Os aseguro que el grano de trigo sigue siendo un único grano, a no ser que caiga dentro de la tierra y muera", de Jn 12, 24? Las palabras que emplea Fray Luis parecen sugerirlo así.

53. "con el calor del espíritu fructifique etc". En el $3^{\text {er }}$ nacimiento: Cristo nació en la Resurrección, decía Fray Luis que en el Cuerpo de Cristo, al resucitar: a) "Se forjaron espíritus vitales": nota 3; b) que "recibió cualidades de espíritu": nota 7; c) "que (el espíritu) le bañó todo de alma": nota 32, y passim el mismo sentido, y que todo esto sucedió porque Cristo dio licencia a su gloria para que lo invadiera totalmente. Aquí, "el calor del espíritu" (de Jesús) hace que este alimento fructifique y dé la verdadera vida.

54. BAC 726; AP 469-470. 
cunstanciales: "de poder", “de saber", "de misericordia”, "de amor infinitos".

Juliano no puede por menos de añadir, como haciendo un recuento de toda la enumeración, que esto fue un "ejemplo jamás oído ni visto".

c) Afirma, en participio pasado, que Cristo no se contentó con: haber nacido, haber muerto, haber re-nacido. Y concluye con un estar siempre a la diestra del Padre, para defensa y amparo de los hombres.

d) A los infinitivos, "a modo de enclítico": poner-lo, encerrar-lo, chuparle, atraer-los, les precede esta introducción, que amplía y aclara su sentido:

Juliano anota que todo esto lo hizo Cristo "para regalo y consuelo (de los hombres) (y) para que le "tengan" siempre, no solamente presente, sino que le "puedan" abrazar consigo mismos, etc...".

En la anotación que precede, puede apreciarse que emplea dos subjuntivos: tengan, puedan, solos y secos, precedidos del pronombre personal le, que les da un cariz y un significado "semejante al proclítico", y que balancean un tanto la fuerza y el sentido de los cuatro verbos anotados.

e) De nuevo el presente de indicativo: Cristo se presenta, nace, en figura de manjar y de trigo.

f) El presente de subjuntivo, precedido también del mismo pronombre le, lo emplea cuando dice que todo esto acontece para que así le-coman, y (le)traguen, y (le)- traspasen.

Juliano emplea luego el subjuntivo normal, y explica que todo esto se realiza en el interior, "con el calor del espíritu, para que (Cristo) fructifique y nazca" en los hombres de otra manera, es decir, por la gracia en el alma y vida de los justos, tema del quinto nacimiento.

$5^{\circ}$ NACIMIENTO: CRISTO NACE EN EL ALMA DEL JUSTO

Juliano calló.

Y Sabino dijo sonriéndose:

"Habéis dicho grandes cosas hasta ahora, sin lo que os resta, que no debe ser menos, aunque en ello tengo una duda aun antes que lo digáis" 1.

Juliano comenzó presentando el tema del Quinto Nacimiento: Cristo nace en el alma del justo. 


\section{Introducción}

Juliano argumentó de esta manera: ¿"No entendéis que nace en nosotros Cristo, cuando Dios santifica nuestra alma"?

En el discurso del diálogo, precede una premisa introductiva de Sabino, quien aduce, a este efecto, dos textos de la Escritura:

Recuerda, en primer lugar, aquellas palabras de San Pablo a los Gálatas: Hijuelos mios, por quienes sufro de nuevo dolores de parto, hasta que se forme Cristo en vosotros ${ }^{2}$.

Y comenta:

"Es decir, que así como el ánima ...se convierte al bien y se va desnudando de su malicia, así Cristo se va formando en ella y naciendo" 3 .

En segundo lugar, aduce el paso del Evangelio de Mateo:

"De los que le aman y cumplen su voluntad, dice Cristo que son su padre y su madre" 4 .

Sabino explica luego que el nacer nosotros en Cristo y el nacer Cristo en nosotros expresa, fundamentalmente, la misma idea. Sabino razona así:

"Como cuando el ánima... se santifica, se dice que nace en ella Jesucristo, así también se dice que ella nace en Él; por manera que es lo mismo, a lo que parece, nacer nosotros en Cristo y nacer Cristo en nosotros, pues la razón... es la misma " 5 .

No obstante, las palabras de Sabino: "Se dice", "a lo que parece", y las palabras finales: "Y de nuestro nacimiento en Jesucristo ayer ${ }^{6}$ dijo Marcelo lo que se puede decir. $\mathrm{Y}$ así no parece, Juliano, que tenéis más que decir en

2. Gal 4,19. Pablo concluye llamando hijos a los mismos que poco antes ha llamado hermanos en la fe. Piensa, tal vez, ahora, que será necesario, un nuevo nacimiento en la fe, "hasta que Cristo tome forma definitiva en ellos" (v.19). En 1 Cor 4,15 expresa el Apóstol la misma idea de "paternidad en la fe". El paso aducido responde a 1Cor 3,6: "Yo planté... sembré etc.," la nueva vida del Espíritu, que os configura con Cristo.

3. BAC 727; AP 471: "así como el ánima... se convierte... se va desnudando... se va formando etc": Veremos cómo Fray Luis insistirá más adelante, una y otra vez, en la misma idea de la "necesidad de la completa desnudez" para unirse totalmente a Cristo.

4. Mt 12, 49-50. Fray Luis cita el texto de Mateo al sentido. En efecto, Jesús responde a quienes le interrumpen:

"Ahí fuera están tu madre y tus hermanos, que quieren hablar contigo" $(12,47)$, con estas palabras: "El que cumple la voluntad de mi Padre... ése es mi hermano, mi hermana y mi madre" (v.50). Quiere expresar, sin duda, que el que cumple la voluntad de su Padre es "todo esto" para Él: Padre, madre etc. De todos modos, la idea aducida aquí por Fray Luis "madre" y "padre", la hallamos también en San Pablo (v. 1Tes 7,11).

5. BAC 727; AP 471.

6. En Padre del siglo futuro, que trata de "nuestro segundo nacimiento": en la vida sobrenatural. 
ello. Y ésta es mi duda" ${ }^{7}$, indican un matiz de inseguridad en él, y ello da pie a Juliano para profundizar en el diálogo.

\subsection{Transitoriedad y unión definitiva}

El razonamiento de Juliano comienza con una premisa que incluye dos partes:

$1^{a}$ ) "Es verdad (comenta) que esos nacimientos andan juntos y que siempre que nacemos nosotros en Dios, nace Cristo en nosotros, y que la santidad y la justicia y la veneración de nuestra alma es el medio de ambos nacimientos".

Mas Juliano advierte diversos matices entre ambos nacimientos.

$\left.2^{a}\right)$ Observa, en efecto:

1. "El nacer nosotros en Cristo es propiamente, quitada la mancha de culpa,... recibir la gracia y la justicia que cría Dios en nosotros, que es como una imagen de Cristo y con que nos figuramos de su manera" 8 .

2. En cambio, el nacer Cristo en nosotros, además de la gracia, "el mismo Espíritu de Cristo: viene a ella, se junta con ella, y como si fuese alma del alma ${ }^{9}$, se derrama... en ella, se apodera de sus potencias y fuerzas, no de paso, $n i$ de corrida, $n i^{10}$ por un tiempo breve, como acontece en los resplandores de la contemplación y en los arrobamientos de espíritu, sino de asiento y sosiego estable, y como se reposa el alma en el cuerpo; que Él mismo lo dice así: El que me amare, será amado de mi Padre, y vendremos a él y haremos asiento en él" 11.

7. BAC 727; AP 471.

8. "figuramos" = configuramos, tomamos la figura o imagen.

9. "el mismo Espíritu de Cristo... y como si fuera alma del alma": Hallamos ya esta misma idea en San Agustín = En el sermón 62,2 dice: "Como el alma es la vida del cuerpo, así Dios es la vida del alma". Inversamente, dice: "El abandono de Dios es la muerte del alma, el abandono del alma es la muerte del cuerpo". Y también: "La vida del cuerpo es el alma; la vida del alma es Dios" (sermón 65, 5). El mismo concepto expresa el Santo en los sermones 156,6; 161,5; 180,$8 ; 212,1 ; 348,3$, y passim en muchos sermones. La idea puede haber inspirado este paso de Fray Luis.

10. "no", "ni", "ni": Fray Luis enfatiza, una y otra vez, la transitoriedad de la presencia: "en el nacer nosotros en Cristo", para contrastarla con la estabilidad o permanencia de esta misma presencia: "en el nacer Cristo en nosotros", cuando el Espíritu de Jesús vive y actúa definitivamente en el alma.

11. Jn 14,23. En este paso, aducido por Fray Luis, Cristo habla de una "presencia estable": del Padre, de Jesús y de su Espíritu, en aquellos que cumplen su palabra, o que lo aman porque cumplen su palabra. Por el contrario, el Espíritu de Jesús no puede morar en aquellos que no escuchan y no aman a Cristo (v. Jn 8,37.43.47). 


\subsubsection{Suspensión y arrobamiento en los místicos}

Aunque dura más que la suspensión, la idea de la brevedad del arrobamiento la hallamos también en santa Teresa de Jesús:

Las potencias y los sentidos, dice la Santa, van "poco a poco muriéndose a estas cosas exteriores, y perdiendo los sentidos y viviendo a Dios".

Es éste, por tanto, un estado breve para llegar a vivir definitivamente para Dios, pues el alma, anota la Santa, "parece se olvida de animar en el cuerpo... y, si dura, quedan los nervios con sentimiento" 12 .

A todas luces, por tanto, en la mente de Santa Teresa, el arrobamiento tiene también carácter pasajero.

La misma doctrina de la transitoriedad de los pasos previos para la unión definitiva, la hallamos también en el Cántico Espiritual de san Juan de la Cruz, "porque los que han llegado ya (dice) tienen toda la comunicación hecha en paz y suave amor, y cesan los arrobamientos, que eran comunicaciones (transitorias) y disposición para la total comunicación" ${ }^{13}$ con Dios.

\section{En resumen:}

Nacer nosotros en Cristo, significa: "recibir su gracia y figurarnos en ella".

Nacer Cristo en nosotros, en cambio, implica además:

"Venir Él por su Espíritu a vivir en nuestras almas y cuerpos", es decir "venir a vivir, y no sólo a hacer deleite y regalo".

Nacer Cristo en nosotros, por lo tanto, "propiamente consiste en que comience a vivir el Espíritu de Cristo en el alma" ${ }^{14}$.

En otras palabras, en el nacer Cristo en nosotros:

a) "El Espíritu de Jesús se une ${ }^{15}$ con la esencia del alma, b) y comienza a ejercitar su virtud en ella, abrazándose con ella sin que ella lo sienta ni entienda. c) Y reposa...en el centro de ella, d) y... derrama... su virtud por toda ella, e) y ${ }^{16}$ la mueve secretamente, f) y con su movimiento de Él y con la obediencia del alma... se hace por momentos mayor lugar y más ancho y dispuesto aposento, movimiento del Espíritu y obediencia del alma".

12. Santa Teresa, Cuentas de Conciencia, 58,7.8.

13. SAN JUAN DE LA CRUZ, Cántico Espiritual $B, 13,6.7$.

14. BAC 728; AP 472-473.

15. "se une": en el texto = se ayunta: BAC 728; AP 474.

16. "y": Obsérvese cómo multiplica esta conjunción (polisíndeton), recurso muy frecuente en Fray Luis, cuando quiere dar mayor fuerza a la expresión. Aquí trata de expresar la multitud 
La cooperación indispensable del hombre, de su entendimiento y la obediencia de su voluntad a la acción del Espíritu, la hallamos claramente ya en san Agustín, por ejemplo en todo el gran tratado De la Trinidad ${ }^{17}$. Especialmente la segunda parte, libros octavo al décimo quinto, de carácter preferentemente especulativo, es un gigantesco esfuerzo del Santo para aclarar el misterio trinitario por la semejanza que de él se halla en el alma humana.

Lo mismo se desprende de la doctrina de santa Teresa de Jesús en las Moradas. Aunque la ascesis predomina en el grupo inferior ${ }^{18}$, la colaboración humana ha de acompañar también, aunque de diferente manera, durante todo el proceso de interiorización o de ascensión del alma hacia Dios en las últimas Moradas.

\subsubsection{Nacer nosotros en Cristo. Presencia fugaz del deleite}

Juliano aduce el texto de Isaías: Regocíjate y alaba, hija de Sión, porque el Señor de Israel está en medio de $t i^{19}$.

1. Precisa que en el nacer nosotros en Cristo, "en las luces de la oración y en sus gustos, todo su trato de Cristo es con las potencias del alma... entendimiento... voluntad y memoria, de las cuales a las veces,... de la copia de razones que el alma siente y está colmada, pasan al compañero las sobras".

Pero anota que todo esto "tiene condición de relámpago... que luce y pasa en breve" 20 .

Fray Luis ofrece la "razón psicológica" de esta brevedad:

de bienes que produce la presencia del Espíritu de Cristo en el alma. Véase el empleo de este mismo recurso en la primera parte de este estudio: "Introducción, nota 31; Tercer nacimiento, nota 23 y arriba, Cuarto nacimiento, la nota 46 y el texto correspondiente a estas notas citadas, y passim en muchos pasos de los Nombres.

17. SAn Agustin, De la Trinidad, 9, 1,1; 15, 2,2. Ver especialmente el epílogo de la obra: $15,28,51$, donde se aprecia la actitud de búsqueda incesante del Santo en la investigación del misterio trinitario.

18. Ver Santa Teresa, Moradas primeras, 2,8 , y el contexto mismo de las tres primeras Moradas sobre todo.

19. Is 12,6. En este ejemplo, aducido por Fray Luis, Isaías habla de la dicha del pueblo que tiene a Dios como su centro, y, por ello mismo, no tiene temor alguno de que esta felicidad se disminuya o se pierda.

20. BAC 728-729; AP 473-474. Obsérvese la precisión y belleza de la expresión: "las potencias... pasan al compañero las sobras", para indicar la multitud de bienes y deleite que experimenta el alma en su trato con Cristo, y que comunica al cuerpo, "su compañero", la abundancia de estos mismos bienes que ella posee. 
"Porque nuestras potencias y sentidos... tienen precisa necesidad de divertirse ${ }^{21}$ a otras contemplaciones y cuidados, sin los cuales ni se vive, ni se puede ni debe vivir".

\subsubsection{Nacimiento de Cristo en nosotros. Acción continua de Cristo}

2. En el nacimiento de Cristo en nosotros, "el Espíritu de Cristo hace (además) las veces ${ }^{22}$ de alma moviéndola a obrar,... y pone en ella ímpetu ${ }^{23}$ para que se menee; y así ${ }^{24}$ obra Él en ella y la mueve, que ella... obra con Él juntamente".

\subsubsection{Presencia en la oración. Reposo de las potencias}

Juliano continúa:

"Mas en la presencia que de sí hace en la oración a los buenos por medio del deleite y de la luz,... el alma y sus potencias reposan, y Él sólo obra en ellas por secreta manera un reposo y un bien que decir no se puede" 25 .

$\mathrm{Y}$ anota, en resumen, la diferencia entre los dos nacimientos:

1) a) "Aquel primer ayuntamiento es la vida,

b) mas éste segundo es el deleite y regalo;

2) a) aquél es el ser y el vivir,

b) aquéste es lo que hace dulce el vivir;

3) a) allí recibe vivienda ${ }^{26}$ y estilo de Dios el alma,

b) aquí gusta algo de su bienandanza;

4) a) aquello se da... para que dure,

b) esto se da, pero... porque es más gustoso que necesario".

21. "necesidad de divertirse" = necesidad de cambiar. En efecto, psicológicamente, las potencias y sentidos no pueden permanecer largo tiempo en su máximo grado de intensidad sin cambiar a otras cosas.

22. "hace las veces": En el texto = "tiene vez".

23. "pone en ella ímpetu" = le comunica fuerza o virtud, etc.

24. "y así" = y de tal manera, de tal modo, de esta manera. Es ilativo. Ver en la primera parte del presente estudio: Primer nacimiento, nota 37; Segundo nacimiento, nota 69, y el texto correspondiente a estas notas citadas.

25. "un bien que decir no se puede" = Nuevamente recuerda Fray Luis la imposibilidad de explicar con palabras humanas lo inexplicable: los misterios divinos. Hemos visto muchas veces esta misma idea en la primera parte del presente estudio.

26. "allí recibe vivienda" = recibe el modo de vivir. 
En resumen:

"Este deleite, en cuanto dura, quita el obrar y lo muda en gozar" 27.

Alterna, como se ve, uno y otro nacimiento: Nacer nosotros en Cristo y Nacer Cristo en nosotros, porque se hallan íntimamente relacionados entre sí.

\section{2. ¿Cuándo nace Cristo en nosotros? La mirada interior}

1) Aspecto negativo-positivo.

Presenta, en primer lugar, el tema en sentido negativo-positivo, y anota luego una premisa de carácter general:

Cristo nace en nosotros siempre que nuestra alma "volviendo los ojos a la consideración de su vida, y viendo las fealdades de sus desconciertos y aborreciéndolos, y considerando el enojo merecido de Dios, y doliéndose de él...".

Volviendo los ojos, etc...: Es, en realidad, el principio fundamental de la interioridad agustiniana:

"No quieras derramarte fuera; entra dentro de ti mismo, porque en el hombre interior reside la verdad;... trasciéndete a ti mismo" 28 .

Pero Fray Luis subraya la necesidad de "permanecer" en la mirada interior. Para lograr este fin, prodiga el empleo del gerundio, que indica la idea en abstracto, pero como realizada en presente. Alterna, para ello, el gerundio simple: volviendo, viendo, considerando, con el gerundio enclítico: aborreciéndo-los, doliéndo-se, queriendo subrayar, sin duda, que el "volver los ojos a la... propia vida", el "mirar los propios desconciertos", el "considerar... los enojos de Dios", ha de realizarse permanentemente, en todo el proceso del nacimiento de Cristo en nosotros.

2) Aspecto positivo.

A la presentación del aspecto positivo precede también una premisa de carácter general:

El alma, "ansiosa de aplacarle, se convierte con fe, con amor, con dolor, a la misericordia de Dios y al rescate de Cristo".

Cristo nace en nosotros entonces, "porque... entra en nuestra alma su mismo Espíritu que, en entrando: a) se entraña en ella, b) y produce... en ella

27. El P. Felix Garcia anota con acierto: "Estas páginas, tan hondas y sutiles, bastarían para conferirle a Fray Luis el título de escritor místico, que conoce, con saber de ciencia, los grados de oración y los fenómenos de la vida de unión con Dios": BAC 729, nota 154.

28. SAn Agustin, De la verdadera religión, 39,72. Ver también el célebre paso de las Confesiones, 10, 27,38, afín a éste: "Tarde te amé...Tú estabas dentro y yo fuera... etc". 
su gracia, que es como un resplandor y como un rayo,... c) y... se asienta en el alma d) y la hace hermosa. e) Y así comienza a tener vida allí Cristo, esto es, comienza a obrar en el alma y por el alma" 29.

Hace luego una reflexión y paralelo sobre la persona de Cristo, como Dios (Verbo) en el Padre, y como hombre, naciendo en nosotros:

1) "Y de esta manera, el que es en sí siempre en el seno del Padre, antes de todos los siglos,

2) comienza... a vivir en nosotros;

1) el que nació de Dios perfecto y cabal,

2) comienza a ser en nosotros como niño,...

1) porque el mismo que es en sí,...

2) en nosotros nace... y... en lo que hace a nosotros, se mide con nuestro sujeto" 30 .

\subsection{El Espíritu de Jesús vive en la interioridad. Despojo y desnudez}

Fray Luis insiste, una y otra vez, en que el Espíritu de Jesús vive en la interioridad del hombre, pero se halla condicionado, en cierto modo, a las disposiciones del alma para obrar en ella: al despojo y desnudez de sí misma etc.

El Espíritu, dice, “aunque está en el alma todo Él,...obra conforme a como (ésta) se rinde y se desnuda de su propiedad ${ }^{31}$.....Mas cuanto el alma, movida y guiada por $\mathrm{É}^{32}$, se le rinde más y se desnuda más de lo que tiene por suyo, tanto ${ }^{33}$ crece en ella más cada día, esto es, tanto va ejecutando en ella su eficacia, y descubriéndose más, y haciéndose más robusto, hasta que llega en nosotros a edad de perfecto varón, a medida de la grandeza de Cristo ${ }^{34}$; esto es, hasta que llega Cristo a ser,... en nosotros... perfecto cual lo es en sí mismo" 35 .

29. BAC 729-730; AP 475. Obsérvese la abundancia de la conjunción copulativa "y": ver la nota 16.

30. "lo que hace a nosotros se mide con nuestro sujeto" = Velada referencia al principio escolástico: "Lo que se recibe, se recibe de acuerdo al modo del recipiente".

31. "se desnuda de su propiedad" = "se desnuda de sí misma": ver la misma idea en la nota 3.

32. "movida y guiada por Él": En todo el proceso de ascensión hacia Dios, incluso a la obra que parecería corresponder exclusivamente al alma, es necesaria siempre la ayuda de la gracia.

33. "cuanto-tanto" = términos correlativos: ver las notas 3 y 31 .

34. Ef 4,13 .

35. BAC 730; AP 476. 
El pensamiento de Fray Luis es muy claro. Casi al comienzo de este quinto nacimiento anotaba:

"Así como el ánima... se convierte al bien y se va desnudando de su malicia, así se va formando en ella Cristo y naciendo" ${ }^{36}$.

Ahora insiste de nuevo en la misma idea y emplea para ello las dos palabras correlativas tanto-cuanto, para subrayarla: Cuanto el alma se desnuda más de lo que tiene de suyo, tanto crece en ella, se hace más robusto, (el Espíritu de Cristo) hasta que Cristo llega a ser perfecto en nosotros.

Consiguientemente, el crecimiento gradual de Cristo en nosotros se halla ordinariamente condicionado al despojo progresivo del alma.

La edad de perfecto varón, a la medida de la grandeza de Cristo, lleva consigo, por lo tanto, la exigencia previa de la total desnudez personal.

\subsubsection{La desnudez en san Juan de la Cruz}

San Juan de la Cruz subraya fuertemente esta misma doctrina cuando habla de la desnudez espiritual.

1) El Santo nos habla en la Subida del Monte Carmelo:

-De la dichosa ventura que tuvo el alma "en desnudar el espíritu de todas las imperfecciones espirituales y apetitos de propiedad en lo espiritual" 37 .

-Nos dice que "el amor es obrar en despojarse y desnudarse por Dios de todo lo que no es Dios" 38 .

-Que "para entrar el alma por esta puerta de Cristo... primero se ha de angostar y desnudar la voluntad en todas las cosas sensuales y temporales, amando a Dios sobre todas ellas" ${ }^{39}$.

2) Y, en la misma Subida, hablando de las aprehensiones imaginarias naturales, como desproporcionado medio para la unión con Dios, afirma:

-Que "primero tratamos de desnudar los sentidos exteriores de las aprehensiones naturales de los objetos... y luego comenzamos a desnudar esos mismos sentidos de las aprehensiones exteriores sobrenaturales" 40.

3) Y al tratar de las disposiciones del alma para llegar en breve a la divina unión:

36. BAC 727; AP 471. Ver arriba, notas 3.31 y 33

37. San JuAN DE LA CRUZ, 2Subida del Monte Carmelo, $1,1$.

38. 2Subida, 5,7 .

39. 2 Subida, 7,2, explicando a Mt 7,14.

40. 2 Subida, 12,1 . 
-"Da avisos y doctrina... para que sepan... quedar en la suma desnudez y libertad de espíritu, cual se requiere para la divina unión" ${ }^{41}$.

-Describe las "canciones en que canta el alma la dichosa ventura que tuvo en pasar por la noche de la fe, en desnudez y purgación suya, a la unión del Amado" 42.

-No tratamos aquí, dice también, "de carecer de cosas... sino de la desnudez del gusto y apetito de ellas, que es lo que deja al alma libre y vacía de ellas, aunque las tenga" ${ }^{43}$.

-La disposición para esta unión, nos dice así mismo: "no es... sino la pureza y amor, que es desnudez y resignación perfecta de lo uno y de lo otro sólo por Dios" ${ }^{44}$.

-Precisa que si el alma no llega a la total pureza, "nunca llega... pues no ha llegado a tener la desnudez y vacío de sus potencias, cual se requiere para la verdadera unión" 45 .

4) Y en el capítulo séptimo de la Subida, trata "de cuán angosta es la senda que guía a la vida eterna y cuán desnudos y desembarazados conviene que estén los que han de caminar por ella. Comienza a hablar de la desnudez del entendimiento" ${ }^{46}$.

5) En la Noche oscura, nos dice que "no se puede venir a esta unión sin gran pureza, y esta pureza no se alcanza sin gran desnudez de toda cosa criada y viva mortificación" ${ }^{47}$.

6) Y en el Cántico espiritual, nos recuerda:

_"Que la satisfacción del corazón no se halla en la posesión de las cosas, sino en la desnudez de todas ellas y pobreza de espíritu" 48 .

-Que por la perfección se encuentra al "Amado en unión de amor, después de la desnudez de espíritu, acerca de todas las cosas”, ${ }^{49}$ y que la perfección evangélica es la desnudez y vacío de sentido y espíritu ${ }^{50}$.

7) En Dichos de luz y amor, enseña:

41. Subida, 1 rótulo.

42. Subida, 2 argumento.

43. 1 Subida, 3,4 = ver arriba, notas 3.31.33.

44. 2Subida, 5,8.- El mismo pensamiento hallamos ya en el Kempis, 1. 3, c. 32, n. 1: "Déjalo todo y lo hallarás todo" o "Dejar todo por "El Todo".

45. 2 Subida, 5,11 .

46. 2 Subida, c.7 título.

47. SAN JUAN DE LA CRUZ, 2Noche Oscura, 24,4.

48. SAN JuAn de la Cruz, Cántico Espiritual B, 1,14.- Pensamiento afín a éste hallamos también en SAN AGUSTIN, aunque en un contexto distinto: "Es mejor necesitar poco que tener mucho": Regla, c. 3, n.18.

49. San JuAn de la CRuz, Cántico..., B 25,4.

50. SAN JUAN DE LA CRUZ, Llama de amor viva, $3,47$. 
Que el seguir a Jesucristo "es hacerse semejantes a Él en la vida, condiciones y virtudes y en la forma de la desnudez y pureza de espíritu".

-Nos dice, finalmente, que "el amor no consiste en sentir grandes cosas, sino en tener grande desnudez, y en padecer por el Amado" 51.

Textos afines a éstos, podrían entresacarse indefinidamente en los escritos del Santo.

En breves palabras, san Juan de la Cruz nos habla:

De la felicidad del alma en la desnudez de espíritu; del amor en despojarse y desnudarse de todas las cosas por Dios; de la desnudez de las aspiraciones naturales y sobrenaturales para llegar a la libertad de espíritu; de la desnudez y vacio de las potencias para llegar a la vida eterna y a la perfección evangélica.

Afirma que el lleno de Dios (del corazón) únicamente se realiza en la desnudez, pureza de espíritu y en padecer por el Amado ${ }^{52}$.

La enseñanza que se desprende de todos los textos es, fundamentalmente, la misma:

Cristo obra en nosotros (en el alma) tanto cuanto ésta se le rinde y se desnuda de su propiedad (de sí misma).

En otras palabras: El lleno de Dios, para el Santo, es proporcionado al vacío y desnudez que el hombre realiza en sí mismo.

La idea de asemejarse a Cristo por el sufrimiento y por la total desnudez y entrega de sí mismo, la hallamos ya fuertemente subrayada al finalizar el siglo primero o principios del segundo en san Ignacio de Antioquía, especialmente en las Epístolas a los Efesios y a los Romanos.

Para él, la perfecta unión con Cristo solamente se consigue en el despojo total, incluida la entrega de la propia vida por Él ${ }^{53}$.

\subsubsection{No en igualdad, sino en manera semejante}

Fray Luis insiste en el tema y aclara que el llegar a la perfección del varón perfecto según Cristo, no se realiza "en igualdad precisa, sino en manera semejante;... que el vivir que tiene en nuestra alma Cristo, cuando llega a ser en ella varón perfecto, no es igual en grandeza y al obrar que

51. SAN JUAN DE LA CRUz, Dichos de luz y amor, prólogo.

52. Dichos..., 119.

53. SAn IgnaCio de Antioquia: ver, por ejemplo, Efesios, 3,1; Romanos, 5,3 a 6,3 y, prácticamente, todo el contexto de la Carta a los Romanos. 
tiene en sí... y,... aunque reposa en nuestra alma todo el Espíritu de Cris-to,... obra...: 1) primero como niño, 2) y luego como más crecido, 3) y después como valiente y perfecto" 54 .

Aduce, como ejemplo, el modo progresivo de actuar el alma en el cuerpo ${ }^{55}$, para explicar los dos párrafos anteriores.

Explica cómo el alma, simple en sí misma, comienza al mismo tiempo que el cuerpo, pero no ejerce toda su potencialidad desde el principio:

"No ejercita (dice) toda su eficacia y su vida, sino después y sucesivamente,... así... Cristo,... aunque pone en nosotros todo su espíritu cuando nace, no ejercita luego...t oda su vida, sino... conforme a como... le seguimos y nos limpiamos ${ }^{56}$ de nosotros mismos".

$Y$ repite, de nuevo, el mismo tema:

Cristo nace en el alma cuando comienza a vivir en ella; vive más cuando crece; es perfecto cuando llega a vivir allí al estilo que vive en sí.

El nacimiento y crecimiento de Cristo en nosotros tiene, por lo tanto, tres grados:

1) En el primero, de niño, "comprendemos... lo principiante y aprovechante... y (Cristo) vive en la parte más alta del alma".

2) En el segundo, de más perfecto, Cristo vive y actúa "en aquélla y en la que llamamos inferior".

3) En el último, de perfecto totalmente, Cristo actúa "en esto y en todo el cuerpo del todo".

$\mathrm{Y}$ enumera los tres estados, que va a desarrollar ampliamente a continuación:

\subsection{Estados de ley, de gracia, de gloria}

1) "El primero (dice) es el estado de ley.

54. BAC 730; AP 476.

55. Fray Luis parte del concepto tradicional de la palabra "alma", como principio que dirige los procesos vitales en todo el organismo vivo, en sus tres aspectos fundamentales: a) Principio "simplemente vital" en los vegetales; b) principio "de la sensibilidad" en los animales; c) principio superior del hombre, "racional o espiritual". En el hombre, sin embargo, el mismo y único principio realiza las funciones más complejas y entrelazadas: vitales, sensitivas, racionales o espirituales.- Véanse, respecto a esto, las obras: El hombre, su grandeza y tragedia, de FrANCISCO ARASA, libro de cultura inmensa, de carácter general, sobre el hombre y su problema en el mundo actual: "Aspecto psicológico", "científico", "técnico", "religioso". "Ed. Círculo de Lectores". Barcelona 1969 etc.; y el denso estudio: Cuerpo y alma. Estructura dinámica del cuerpo humano, de PEDRo LAIN ENTRALGo, tema más específico, hasta donde la ciencia puede llegar en su relación con la fe. "Ed. Espasa Calpe". Madrid, 1991.

56. "limpiamos": en el texto ="apuramos". 
2) El segundo es el estado de gracia.

3) $\mathrm{Y}$ el tercero... estado de gloria" 57 .

Fray Luis presenta, una vez más, la naturaleza del alma, como base explicativa de la doctrina que va a presentar después. En nuestra alma, dice "hay dos partes 58 :

$1^{a}$ ) "Una divina, que, de su hechura y metal ${ }^{59}$, mira al cielo y apetece... lo que es razón y justicia; (es) inmortal de naturaleza, y muy hábil para... la contemplación y... el amor de las cosas eternas".

$2^{a}$ ) "Otra de menos quilates : a) que mira a la tierra b) y que se comunica con el cuerpo, con quien tiene deudo ${ }^{60} \mathrm{y}$ amistad, c) sujeta a las pasiones y mudanzas de él, que la turban y alteran en diversas olas de afectos; d) que teme, que se acongoja,... codicia,... llora,... se engríe y ufana e) y que... no puede hacer sin su compañero estas obras".

Y concluye:

"Estas dos partes son... de ordinario entre sí contrarias, y riñen, y se hacen guerra" 61 .

En la mente de Fray Luis, es necesario que se guarde la jerarquía de valores entre las dos almas para que subsista la paz:

Siendo la ley, dice, "que esta segunda se gobierne siempre por la primera, a las veces,... rebelde y furiosa, toma las riendas ella del gobierno y hace fuerza a la mejor; lo cual es vicioso" 62 .

Aclara, finalmente, que son "la una como el cielo, y la otra como la tierra, y como un Jacob y un Esaú, concebidos juntos en un vientre ${ }^{63}$, que entre sí pelean".

La misma doctrina se desprende de los escritos de santa Teresa de Jesús, aunque deja entrever la dificultad en hablar del espíritu ${ }^{64}$ :

57. BAC 731; AP 476-477.

58. "hay dos partes" = Fray Luis habla aquí de las dos tendencias, buena y mala, de que habla el Apóstol a los Romanos, 7,15.19: "No hago lo que quiero, sino lo que no quiero". Téngase en cuenta, no obstante, lo dicho en la nota 55.

59. "de su hechura y metal" = condición natural, es decir: por su condición natural.

60. "con quien tiene deudo" = con quien tiene parentesco: P. FeliX Garcia, BAC 731 nota 160 .

61. "Estas dos partes son... contrarias, y riñen, y se hacen la guerra". Este concepto lo desarrollará Fray Luis ampliamente más adelante, al citar el paso de la Escritura sobre el antagonismo entre Esaú y Jacob.

62. BAC 731; AP 478.- Véase San Agustin, La Ciudad de Dios, 19, 13,1, donde el Santo hace una síntesis maravillosa y progresiva, de los diversos aspectos necesarios para que pueda darse la paz.

63. "concebidos juntos en un vientre" = hermanos gemelos.

64. SANTA TERESA anota, por ejemplo, en la Vida, 11,6, que el "lenguaje de espíritu es tan malo de declarar...". 
En el Libro de la Vida nos dice la Santa que "querría declarar... la diferencia que hay cuándo es espíritu bueno y cuándo malo" 65 . Afirma que el "espíritu lleva tras sí (al cuerpo)... con suavidad grande" 66; que, a su parecer, aunque todo sea uno, hay alguna diferencia del alma al espíritu.

En las Moradas nos dice que "en alguna manera le parecía había división en su alma" ${ }^{67}$.

$\mathrm{Y}$ en Cuentas de conciencia sugiere que "el alma y el espíritu debe ser una (misma) cosa" ${ }^{68}$, aunque añade que son cosas "dificultosas de decir" 69 .

"Parecíame se me dio a entender (dice también) que el espíritu era lo superior de la voluntad" 70 .

\subsection{Primer grado: Estado de ley}

\section{a) Parte superior del alma:}

Juliano continúa su diálogo y explica que "cuando el alma aborrece su maldad y Cristo comienza a nacer en ella, pone su espíritu,... en el centro, que es la sustancia del alma, y prende luego su virtud en la primera parte de ella,... la más alta y mejor, y vive Cristo allí en el primer estado de este nacimiento,... alumbrándo-la, y enderezáno-la, y renovándo-la, y dándo-le ${ }^{71}$ salud y fuerzas para que... ejercite su oficio" 72 .

b) Parte inferior del alma:

De la parte inferior, en cambio, dice Juliano que "el espíritu de Cristo... no le desarraiga sus bríos, porque aún no vive en aquesta parte baja; mas, aunque no viva en ella como señor pacífico... desde su lugar algo le da leyes por donde viva, y le hace que se conozca,... y la riñe y la aflige con amenazas y miedos" 73 .

65. Idem, Vida, 25,2.

66. Idem, Vida, 20,7: La Santa habla de la diferencia entre unión y arrobamiento.- Respecto a esto, ver SERgio GonAlez, La Mística Clásica Española. (Estudio místico-literario sobre San Juan de la Cruz y Santa Teresa de Jesús). Bogotá, 1955, especialmente pp. 159-161.

67. Santa Teresa, Séptimas moradas, 1,11. En realidad, todo el contexto de las Moradas, especialmente de las últimas.

68. SAnTA Teresa, Cuentas de conciencia, 58,9 .

69. Idem, Cuentas...,n. 1: La Santa habla aquí de los grados de oración.

70. "lo superior de la voluntad" = parte superior del alma: Idem, Cuentas..., 26,2.

71. De nuevo emplea Fray Luis deliberadamente el gerundio con enclítico = alumbrándo$l a$, y enderezándo-la, y renovándo-la, y dándo-le salud y fuerzas: verbos que expresan una acción progresiva y permanente de Cristo en el alma = ver arriba: 5.2. ¿Cuándo nace Cristo en nosotros? La mirada interior. Veremos que Fray Luis emplea con frecuencia este recurso literario más adelante.

72. BAC 732; AP 478.

73. BAC ib; AP 478-479. 
Como ejemplo explicativo, de la actividad de Cristo en la parte inferior del alma en tal estado, aduce la actitud pedagógica de Moisés con su pueblo:

"Y Cristo en este artículo, se ha ${ }^{74}$ con esta menor parte como Moisén, que le da la ley y la amonesta, y la riñe y la amenaza, y la enfrena; mas aún no la libra de su flaqueza ni la sana de sus malos movimientos. Por donde a este grado o estado le llamamos de ley. En que ${ }^{75}$ como Moisén... gozaba de la habla de Dios, y en la cumbre del monte conversaba con Él, y recibía su gracia y era alumbrado de su lumbre, y descendía después al pueblo carnal e inquieto y sujeto a diferentes deseos, y que ...no veía sino el temblor y las nubes; y descendiendo a él, le ponía leyes de parte de Dios;... así la parte más alta nuestra, luego... que Cristo en ella nace, santificada por Él y viviendo por su espíritu,... al pueblo que está en la falda, esto es, a la parte inferior,... pueblo bullicioso y carnal e inclinado a hacer lo peor, le escribe leyes y le enseña lo que conviene hacer o huir, y le gobierna las riendas, a veces alargándolas, y a veces recogiéndolas hacia sí, y, finalmente, la hinche de temor y amenazas".

Prosigue luego la comparación anterior, y, en cierto modo, preinicia también el segundo estado.

a) "Y como contra Moisén se rebeló por diferentes veces el pueblo y, como siempre puso al yugo su mal domada cerviz, b) así esta parte baja... oye mal.... las amonestaciones de su hermana mayor, en que ya Cristo vive,... y despierta entre sí crueles peleas" ${ }^{76}$.

\subsubsection{Proceso ascético-místico}

1) Aspecto negativo-positivo:

Juliano sigue comentando el paso aducido de la Escritura -el caminar del pueblo de Dios por el desierto- y se vale también de la actitud de Moisés con su pueblo.

Presenta, en primer lugar, el aspecto negativo-positivo del procedimiento empleado:

A) "Como Moisén, para llevar a aquella gente al asiento ${ }^{77}$ de su descanso, a) les persuadió primero que saliesen de Egipto, b) y les metió en la soledad del desierto, c) y les guió... por largo espacio de tiempo" ${ }^{78}$.

74. "Cristo en este artículo se ha" = en esta coyuntura procede.

75. "En que" = en el que, en el cual.

76. BAC ib; AP 479-480.

77. "llevar... al asiento" = al lugar o morada estable.

78. BAC 733; AP 480. 
2) Aspecto positivo:

Luego presenta el aspecto positivo:

En efecto, en su disertación-diálogo, Juliano explica que Moisés ofrecía también a su pueblo el amparo de Dios:

a) "En la nube, b) en la columna de fuego, c) en el maná que les llovían los cielos, d) y en el agua que les manaba la piedra, y cómo les iba levantando hacia Dios, hasta que... pasaron con Josué el Jordán y... reposaron en la tierra (prometida), hasta que vino Cristo a nacer en su carne" 79 .

Y aplica luego el ejemplo aducido a la acción de Cristo en el alma:

B) Así obra el Espíritu de Cristo, cuando "ha nacido ya en lo que es principal en el alma, para reducir a su obediencia la parte que resta,... desde la razón donde vive".

1) Aspecto negativo-positivo:

Comienza primero: a) "Induciéndo-la a que se despida de los regalos de Egipto, b) y lavándo-la con las tribulaciones, c) y destetándo-lä poco a poco de sus toscos consuelos, d) y quitándo-le... las cosas que ama, e) y haciéndola a que ame la pobreza y desnudez ${ }^{80}$ y el desierto".

2) Aspecto positivo:

Y continúa: a) "Dándole allí el maná, b) y pasando a cuchillo ${ }^{81}$... a sus enemigas pasiones, c) va creciendo en ella,... d) y, al fin,... se encarna en ella e) y la hinche de sí, como hizo a la mayor primera" 82 .

Fray Luis emplea aquí el gerundio con maestría literaria inigualable:

Induciéndo-la, lavándo-la, destetándo-la, quitándo-le, haciéndo-la: Cinco gerundios, que presentan la idea en abstracto, pero como realizada en un permanente presente, en todo el proceso previo de purificación, necesario para la ascensión. Cinco gerundios con su complemento "a modo de enclítico", que especifican y concretizan la referencia al alma en todo el proceso de su desnudez previa para la ascensión.

El primero, el segundo y el último: induciéndo-la, levantándo-la, haciéndo-la, aparecen como positivos, pero con significación positivo-negativa. El primero, induciéndo-la a que se despida de los regalos; el segundo, levantándo-la, presenta también un aspecto positivo-negativo; pues la purificación se realiza con tribulaciones; el último, haciéndo-la, de carácter también positivo-negativo, porque invita al alma a que ame la desnudez y el desierto.

79. BAC ib; AP ib.

80. "desnudez y desierto" = ver arriba: 5.3. El espíritu de Jesús vive en la interioridad. Despojo y desnudez, y notas 3.31.33.33a.52, y el texto correspondiente a estas notas.

81. "pasando a cuchillo" = ver ariba: 40 . Nacimiento, nota 45 y texto correspondiente.

82. BAC 733; AP 480-481. 
Los dos gerundios intermedios restantes, destetándo-la, quitándo-la, expresan una idea preferentemente negativa, y contrabalancean un tanto el sentido negativo-positivo de los otros tres.

El último gerundio, finalmente, dándole allí el maná, expresa una idea totalmente positiva, para significar el sosiego en la actividad plena y en la posesión mística del Espíritu de Cristo.

Antes de entrar de lleno en el segundo estado: de gracia, Juliano advierte que, en todo este proceso, Dios no le quita al alma lo que le es natural, "como son los sentimientos,... y el padecer y morir, sino desarráigale lo vicioso... casi del todo" 83 .

Segundo grado: Estado de gracia

Fray Luis resume así el segundo grado, en el cual el Espíritu de Cristo vive en las dos partes del alma:

a) "En la primera,... la celestial, santificándola,... haciéndola como Dios; b) en la segunda, que mira a la carne, apurándola ${ }^{84}$... de lo carnal y vicioso. Y...Cristo ahora pone en ella a cuchillo ${ }^{85}$ casi todo lo que es contumaz y rebelde".

A) Primera parte.

Fray Luis recuerda ahora la actitud de diálogo y amistad de Jesús con sus discípulos. En el diálogo, Juliano razona de esta manera:

Jesús procedió así:

a) "Los conversó ${ }^{86}$ primero, b) los corregía poco a poco... con palabras, con ejemplos, con dolores y penas; c) y, finalmente, después de su resurreción,... envió sobre ellos en abundancia su Espíritu, con que los hizo perfectos y santos".

B) Segunda parte.

Así procede cuando en nosotros nace:

a) "Fortifica primero la razón para que no la venza el sentido,... b) después... derrama su espíritu... sobre toda carne ${ }^{87}$, con que se rinde y sujeta al espíritu".

Juliano concluye:

"Y cúmplese entonces lo que en la oración ${ }^{88}$ le pedimos: que se haga su voluntad, así como en el cielo, en la tierra" 89 .

83. BAC ib; AP 481.

84. "apurándola" = purificándola; ver arriba, nota 56.

85. "pone... a cuchillo" = de nuevo emplea Fray Luis esta frase: ver arriba la nota 81.

86. Jesús "los conversó" = dialogó con ellos: ver P. FÉLIX GARCIA, BAC 734, nota 164.

87. Jl 2, 28. Fray Luis cita según la Vulgata.

88. En la oración dominical: "que se haga su voluntad".

89. BAC 734; AP 482. 
Y ofrece la razón:

"Porque manda Dios en el cielo del alma, y en lo terreno de ella es obedecido casi ni más ni menos; y baña el corazón de sí mismo ${ }^{90}$, y hace ya Cristo en toda el alma oficio enteramente de Cristo, que es oficio de ungir, porque la unge de la cabeza a los pies ${ }^{91}$, y la beatifica en cierta manera,... comunícale mucho de la vida que le ha de durar para siempre, y sostiénela ya con el vivir de su espíritu" 92 .

La vida del alma entonces, en su totalidad, es vida de Cristo, es decir, la misma que ha de vivir en la eternidad.

\subsubsection{Reflexión e invocación mística}

El "alma mística" de Fray Luis hace luego esta reflexión:

"Éste es... el pan que... pedimos a Dios cada día, cuando decimos ${ }^{93} y$ nuestro pan,... nuestro porque nos lo prometes; nuestro, porque sin él no se vive; nuestro, porque sólo él hinche nuestro deseo".

Y añade esta invocación mística:

"Así que, este pan y esta vida que, prometida nos tienes, acorta los plazos, Señor, y dánosla ya, y viva ya tu Hijo en nosotros del todo, dándonos entera vida, porque Él es el Pan de la vida" ${ }^{94}$.

Juliano continúa su diálogo y advierte que "cuando viene a este estado el nacimiento de Cristo en nosotros, y cuando su vida ha subido hasta este punto, entonces Cristo es lisamente en nosotros el Mesías prometido de Dios".

Finalmente resume:

"El estado es de gracia, porque la gracia baña a casi toda el alma; y no es estado de ley, ni de servidumbre, ni de temor, porque todo lo que se manda se hace con gusto; porque en la parte rebelde... vive ya Cristo, que la tiene ca-si pura ${ }^{95}$ de su rebeldía" 96.

90. "baña el corazón de sí mismo" = con su misma persona, es decir, con la unión significada por el nombre de Cristo: "el ungido". Ver las notas afines a ésta: 32.33.33a.

91. "de la cabeza a los pies" = ver esta misma frase: $3^{\text {er }}$. Nacimiento, $3.3=$ Descripción del tercer nacimiento: La Resurrección, nota 33 y el texto corespondiente, en la primera parte de este estudio, donde Fray Luis habla de la profusión de dones concedidos a la naturaleza humana de Cristo en la Resurrección.

92. BAC 734; AP 482.

93. Mt 6,11; Lc 11,3.

94. "así que..." = por tanto, por lo cual; v. Jn 6,34.

95. "casi pura" = casi emendada y purificada.

96. BAC 734-735; AP 482-483. 


\subsubsection{Cinco aspectos del estado de gracia}

Juliano enumera a continuación cinco aspectos del estado de gracia, que recuerdan la "verdad y la vida"; la "santidad y la gracia"; "la justicia, el amor y la paz", que resume el prefacio de Cristo Rey. Lo que en el prefacio se afirma del reino universal de Cristo, al presentar la humanidad y la creación entera al Padre totalmente restaurada, se afirma aquí del reino de Cristo en el alma, cuando se haya realizado el completo sometimiento de la parte inferior, la que mira a la tierra, a la parte superior del alma, la que mira al cielo, es decir, de los sentidos a la razón, y de la razón al Señor, como signo de la realidad del Evangelio en la vida del hombre. Juliano desgrana cinco puntos.

El estado de gracia, por tanto:

1) "Es estado de Evangelio, porque el nacer y el vivir Cristo en ambas las partes del alma, y la santificación de toda ella... es el efecto de la buena nueva del Evangelio, y el reino de los cielos que en él se predica, y la obra propia y señalada, y que reservó para sí solo el Hijo de Dios y el Mesías que la ley prometía" 97 .

Aduce, como prueba, las palabras del cántico de Zacarías:

Juramento que juró Abrahán... de darse a nosotros, para que... le sirvamos en santidad y justicia ${ }^{98}$.

2) "Es estado de gozo, por cuanto reina en toda el alma el espíritu, y así hace en ella sin impedimento sus frutos, que son... caridad y gozo y paz..." 99 .

Y cita el paso de Isaías:

Gozando me gozaré en el Señor, y regocijaráse mi alma en el Dios mío; porque me vistió vestiduras de salud, y me cercó con vestidura de justicia ${ }^{100}$.

3) "Es estado de libertad y de reino,... porque en el primer estado (de ley) estaba la gracia... como encerrada,... mas ahora ya se espacia, y se extiende como señora... del cuerpo" ${ }^{101}$.

Apoya todo esto en las palabras del Apóstol:

La paz de Dios alce bandera, y lleve la corona de vuestros corazones ${ }^{102}$.

97. BAC 735; AP 483.

98. Lc 1, 73-75.

99. Gal 5,22

100. Is 61,10 . En este paso de Isaías, aducido por Fray Luis, el profeta narra el canto de agradecimiento del pueblo elegido por la liberación y salvación experimentada, y por la renovación de la alianza, aludida, tal vez, en los esponsales: "Como novio que se pone la corona o novia que se adorna con sus joyas", que dice al final del mismo versillo.

101. BAC 735; AP 483-484.

102. $\mathrm{Col} 3,15$. 
4) "Es estado de muerte y de vida, porque la vida, que es Cristo, da muerte y degüella a casi todos los afectos y pasiones malas del cuerpo, y vive en los que llegan aquí, (y) da vida a lo alto del alma" ${ }^{103}$.

Cita en apoyo este paso a los Romanos:

Si Cristo está en vosotros, vuestro cuerpo... ha muerto cuanto al pecado, mas el espíritu vive por razón de la justicia ${ }^{104}$.

5) Y, finalmente, "es estado de amor y de paz, porque se hermanan en él las dos partes del alma,... y el sentido ama servir a la razón, y Jacob y Esaú se hacen amigos" 105 .

\subsubsection{De nuevo, el paso de Esaú y Jacob. Ascenso continuo hacia el Señor}

Fray Luis aduce de nuevo el hecho de la Escritura, de Esaú y Jacob, anteriormente citado.

En el proceso del diálogo, Juliano comienza presentando esta premisa:

"Porque... Rebeca... concibió de su vientre ${ }^{106}$ dos hijos,... tenía en su vientre dos linajes de gentes contrarios, que pelearían siempre entre sí, y... el menor en salir a la luz vencería al que primero naciese" ${ }^{107}$.

Y amplía luego la imagen bíblica. En efecto:

a) "Nació primero un niño bermejo ${ }^{108}$ y belloso, b) y después... de él y asido de su pie... nació otro de diferente cualidad del primero".

a) El primero se llamó Esaú, b) el segundo Jacob" ${ }^{109}$.

La inclinación de cada uno fue diferente, como lo era su figura: a) "Esaú, aficionado a la caza y al campo, b) Jacob a vivir en su casa. En ella compró un día... a su hermano el derecho del mayorazgo, que se le vendió por comer ${ }^{110}$. Poco después, con artificio ${ }^{111}$, le ganó la bendición de su padre" ${ }^{112}$.

103. Sigo el orden del título: Estado de muerte y de vida, para mayor claridad.

104. Rom 8,10: Es decir, el Espíritu es vida y fuerza de resurrección.

105. "y Jacob y Esaú se hacen amigos": según la comparación bíblica, que ha presentado anteriormente.

106. "concibió de su vientre"= de un solo embarazo.

107. BAC 736; AP 484.

108. "bermejo" = rubio, pelirrojo.

109. Sigo el orden anterior: Esaú primero, para mayor claridad.

110. "el derecho del mayorazgo, que se lo vendió por comer": El cumpliento del oráculo (respuesta) del Señor a la pregunta de Rebeca: "Hay dos naciones en tu seno...; la una oprimirá a la otra, y el mayor servirá al menor" (Gen 25,23), se narra aquí (Gen 27, 1ss) en forma de drama. Esaú "juró y vendió a Jacob sus derechos de primogénito" (Gen 25,33).

111. "con artificio" = con estudiado engaño.- Véase, a este respecto, SAN AguSTin, La Ciudad de Dios, 16,37, donde habla de las figuras místicas de Esaú y Jacob. Para el Santo, "no es engaño" la actitud de Jacob, sino "misterio": El Santo habla de esto en muchos lugares: ver, por ejemplo, el contexto de los sermones $=4,21 ; 89,5 ; 122,3 ; 229 \mathrm{~F}, 2$.

112. La fuerza de este paso de la Escritura sobre Esaú y Jacob, aducido por Fray Luis, se cifra no sólo en el artificio (engaño) de Jacob para conseguir la primogenitura de Esaú, su her- 
a) "Por esta causa... aborrecía de muerte Esaú a Jacob; amenazábale siempre. b) El mozo santo... 1) huyó la ocasión; 2) desamparóo ${ }^{113}$ la casa del padre; 3) caminó para oriente; 4) vió... el cielo ${ }^{114}$ sobre sí abierto ${ }^{115}$; 5) sirvió... por Lía y por Raquel ${ }^{116} \mathrm{y}$, casado, 6) tuvo abundancia de hijos y de hacienda, y volviendo... a su tierra, 7) luchó con el ángel $\left.{ }^{117}, 8\right)$ fue bendecido de él, y, enflaquecido el muslo $\left.{ }^{118}, 9\right)$ mudó el andar,... 10) y luego vino al encuentro Esaú, su hermano, ya pacífico" 119.

Diez verbos en tiempo pretérito: huyó, desamparó, caminó, vio, sirvió, tuvo, luchó, fue bendecido, mudó, vino, en los que presenta acontecimientos ya concluidos, prósperos y adversos de Jacob, al huir de su hermano, para hacer ver, más adelante, por medio de este paso de la Escritura, las vicisitudes, prósperas y adversas, del alma en su ascenso hacia el Señor.

mano mayor, sino también, y sobre todo, en las consecuencias de este hecho. Los hebreos pensaban, en efecto, en una promesa mayor: la de ser antecesor del Mesías, por el mismo hecho de ser el primogénito. Este hecho ocasiona una rotura entre toda la familia, pero especialmente entre los dos hermanos. Jacob se vale del engaño que le propone su madre para conseguir la bendición de su padre (Gen 27, 6-29) y tiene que huir de su hermano (Gen 27, 43 a 28,5); Esaú, que despreció un día su primogenitura (Gen 25, 32-33), se queda ahora sin nada, por la bendición irrevocable de su padre, la cual, en último término, viene de Dios. Esta rotura, por tanto, sirve a Fray Luis para hacer ver la lucha implacable entre las dos almas: la "que mira al cielo" y la "que mira a la tierra".

113. "desamparó": abandonó", dejó.

114. "vio el cielo" = esta aparición renueva las promesas hechas a Isaac por Jahvé, a quien Jacob invoca ahora como su Dios (Gen 28, 13-16.19,21b).

115. "vio... el ciele sobre sí abierto" (v. Gen 28, 12s). El sueño de la escala o escalera que lleva al cielo es una idea mesopotámica simbolizada por los zigurats, en forma de pirámide escalonada. La aparición une a la tierra con el cielo, lo cual anticipa, tal vez, en la mente de Fray Luis, la sumisión definitiva "del alma terrena o que mira a la tierra", "al alma celestial o que mira al cielo", por la fuerza del Espíritu de Cristo, de lo cual hablará más adelante.

116. Gen 29, 20-28. En el engaño de Labán a Jacob, al faltarle a la palabra dada, de entregarle a Raquel después de haberle servido durante siete años, puede apreciarse, tal vez, también, un castigo por el engaño de él a su padre para hacerse con la primogenitura de Esaú, es decir, engaño por engaño, sin que se quiera justificar la acción de Labán. Ver arriba la nota 112.

117. Jacob "luchó con un ángel" = con un hombre, mejor, con un desconocido, al que la tradición ha identificado, sin embargo, con un ángel, que apareció a Jacob para bendecirle, y que representaba al mismo Dios. La noche favoreció la no identificación del desconocido. Jacob salió vencedor. Con su fe y confianza, Jacob superó aquella "noche, doblemente oscura", salió como un hombre nuevo de aquella lucha y se reconcilió con Dios.- Algunos Padres han querido ver en este episodio una imagen del "combate espiritual" y de la "eficacia de la oración perseverante". Ésta es también, sín duda, la idea que ha querido expresar Fray Luis al recordar aquí este hecho. Ver arriba la nota 115.

118. Gen 32,26. "enflaquecido el muslo" = dislocado el muslo.

119. Gen 33, 1-11: "vino... Esaú ya pacífico": La pacificación entre Esaú y Jacob, por la oración de éste a Dios, indica también, una vez más, la paz y el sosiego definitivos entre la parte del alma "que mira a la tierra" y "la que mira al cielo": ver las notas 115 y 117. 


\subsubsection{Técnica literaria}

Fray Luis, con técnica inigualable, emplea verbos transitivos e intransitivos, con significado y matices diferentes. Veamos:

1) Huyó: generalmente intransitivo = huir de, pero tomado aquí como transitivo: huyó (apartó) la ocasión. Emplea este verbo de manera parecida en la Vida Retirada, cuando habla de la descansada vida, "la del que huye el mundanal ruído".

2) Desamparó: de acción transitiva también = desamparó (abandonó, dejó) la casa del padre.

3) Caminó para: intransitivo = caminó para (hacia), rumbo al oriente.

4) Vio: transitivo = vio (observó) el cielo sobre sí abierto.

5) Sirvió: de acción intransitiva y transitiva = empleado aquí como intransitivo: sirvió (estuvo al servicio de) por Lía y Raquel.

6) Tuvo: transitivo = tuvo (poseyó) abundancia de hijos y hacienda.

7) Luchó: intransitivo = luchó (combatió) con el ángel.

8) Fue bendecido: transitivo = fue bendecido (ensalzado o engrandecido) de (por) él: Ya no te llamarás Jacob (le dice el desconcido más adelante), sino Israel, porque has luchado contra Dios y contra los hombres, y has vencido.

9) Mudó: transitivo = mudó (cambió, sentido figurado), el andar, a consecuencia del combate, porque, "viendo el hombre que no le podía vencer, le tocó en la articulación del muslo, y le descoyuntó durante la lucha".

10) Vino: intransitivo. = Y luego, como consecuencia de todo esto, vino (compareció), finalmente, Esaú, para reconciliarse con su hermano.

En todo este proceso, predominan los "verbos de movimiento": huyó, desamparó, caminó, sirvio, luchó, mudó, vino, sin excluir el mismo aspecto de movimiento en los otros verbos: vio (observó con atención); fue bendecido (precisamente a causa de la lucha con el desconocido); tuvo abundancia de hijos y bienes, como consecuencia de la eficacia permanente de la bendición paterna.

Fray Luis quiere indicar, sin duda, con todo este maravilloso recuento, el esfuerzo continuo que ha de realizar el hombre en su búsqueda y ascensión hacia el Señor.

En la aplicación de la imagen, emplea el mismo procedimiento: Premisa, aplicación propiamente dicha, conclusión.

\section{Premisa:}

Conforme a la imagen bíblica, Juliano anota en su exposición que las dos partes del alma riñen entre sí, "porque de su naturaleza tienen apetitos con- 
trarios; y... después nacen de ella dos linajes de gentes enemigas entre sí: 1) las que siguen en el vivir y el querer del sentido, 2) y las que miden lo que hacen por razón y justicia" 120.

\section{Aplicación:}

En efecto, continúa:

1) a) "El sentido... sigue siempre sus pasiones fieras por alcanzarlas; b) mas la razón... reposa contemplando la verdad con el descanso".

2) a) "Aquí, (dice), vienen a las manos la bendición y el mayorazgo. Enajénanse los sentidos y descubren sus deseos sangrientos contra el hermano, b) que... los huye y corta las ocasiones del mal,... y, puestos los ojos en el oriente, camina a él la razón ${ }^{121}, \ldots$ (y) se le aparece Dios".

3) a) "Y... le mueve y guía a servir muchos años... por Raquel y por Lía, b) hasta que... viene a abrazarle y como a luchar con el ángel, pidiéndole: que lo santifique y bendiga, y ponga en paz sus sentidos,... y, con la bendición, muere el muslo ${ }^{122}$, porque en el morir del sentido vicioso consiste el quedar enteramente benditos".

4) a) "Y cojea luego el hombre b) y es Israel,... porque se ve en él y se descubre la eficacia de la vida divina, que ya se posee; cojo, porque anda en las cosas del mundo con sólo el pie de la necesidad, sin que le lleve el deleite" ${ }^{123}$.

Conclusión:

"Y así ${ }^{124}, \ldots$ el sentido sirve a la razón y se pacifica con ella, y la ama, y gozan ambas, cada una según su manera, de riquezas y bienes; y son buenos hermanos Esaú y Jacob, y vive, como en hermanos conformes, el Espíritu de Cristo, que se derrama por ellos" ${ }^{125}$.

Aduce el salmo 132 como prueba escriturística. Esto es, explica, lo que se dice en el salmo:

120. Fray Luis recuerda aquí al Apóstol = "No hago lo que quiero, sino lo que aborrezco": Rom 7, 15.19 .

121. El relato aducido como ejemplo por Fray Luis abarca en el Génesis desde el cap. 25, 19. al 33, 20.- Ver sobre esto

Cristobal Cuevas, Fray Luis de León. De los nombres de Cristo. "Ed. Cátedra. Letras Hipánicas". 5a. edición. Madrid, 1986, pag. 555, nota 160.

122. "muere el muslo" = muere aquello "que mira a la tierra", es decir, la inclinación viciosa y el sentido vicioso, para quedar sometido a la razón.

123. BAC 737. AP 485-486.

124. "Y asî": es ilativo = de esta misma manera. Fray Luis ha querido, por lo tanto, aducir el paso anterior de la Escritura, pacificación entre Esaú y Jacob, para llegar a esta conclusión: "el sentido sirve, finalmente, a la razón y se pacifica con ella". Ver la nota 24.

125. Esta paz la produce precisamente el Espíritu de Cristo, es decir, es fruto del Espíritu de Cristo. 
¡Cuán bueno es y cuán lleno de alegría el morar en uno los hermanos... etc! ${ }^{126}$.

Afirma, finalmente, que el descanso y la dulzura de esta vida se da "cuando aquestas dos partes nuestras, que decimos humanas, viven también como hermanas en paz y concordia" 127 .

\subsubsection{Interpretación mística del salmo 132}

Fray Luis hace luego una deliciosa interpretación mística del salmo 132 aducido para explicar esta paz anotada:

En efecto, Juliano explica en el diálogo que "es suave y provechosa esta paz como el ungüento oloroso y derramado, y el rocío que desciende sobre los montes de Hermón y de Sión; porque... el Hijo de Dios, que nace y vive en estas dos partes,... que es unción y rocío,... derramándose en la primera de ellas, y de allí descendiendo a la otra y bañándola, hace en ellas esta paz provechosa y gustosa".

Advierte que la parte principal es "como la cabeza, y la otra como la barba áspera, y como la boca o la margen de la vestidura; y la una es verdaderamente Sión, adonde Dios se contempla, y la otra Hermón, que es asolamiento, porque consiste su salud en que se asuele ${ }^{128}$ en ella cuanto levanta el vicioso deseo".

El hombre en quien Cristo nace y vive así, puede decir:

Vivo yo,... vive en mí Jesucristo ${ }^{129}$. "Porque vive y no vive; no vive por sí, pero vive, porque en él vive Cristo;... porque Cristo:... a) le alienta, b) y le mueve, c) y le deleita, d) y le halaga, e) y le gobierna las obras, f) y es la vida de su feliz vida" 130 .

Y, de nuevo, la "técnica literaria" de Fray Luis:

Porque Cristo ha llegado a ser vida de la vida del hombre, le alienta, y le mueve, y le deleita, y le halaga, y le gobierna las obras.

126. El salmo 132 ensalza la convivencia, tanto familiar como nacional. Aunque este salmo se refiere a la bendición que Dios derrama sobre Sión, Fray Luis lo aplica aquí místicamente, por extensión, para cantar la dulzura y el sosiego cuando las dos partes nuestras: "la que mira a la tierra" y "la que mira al cielo", viven en paz y concordia, como explicará a continuación.

127. BAC 737-738; AP 486-487.

128. "se asuela en ella" = se asienta, se aloja o reposa en ella "todo lo que... etc". Parece empleado como "pronominal".

129. Gal 2,20. Fray Luis presenta aquí, como se ve, la vivencia mística del alma, transformada ya en la misma vida de Cristo.

130. BAC 738; AP 487-488. 
Cinco verbos en presente de indicativo. Los cinco verbos expresan la "acción constante" de Cristo en el hombre, en este segundo estado: de gracia, aunque cada verbo expresa la idea con un matiz diferente.

Los cuatro primeros verbos, sin complemento alguno, van precedidos únicamente del pronombre $l e$, "a modo de" proclítico, que dice referencia directa al hombre en el que vive Cristo, expresan la multitud de bienes que Cristo distribuye en el alma en tal estado de gracia.

$\mathrm{Y}$, cierto, al alma (al hombre) que vive en tal estado, Cristo: a) le alienta, es decir: le anima, le infunde valor; b) y le mueve: le menea, le sacude, le persuade; c) y le deleita: le agrada, le place y le complace; d) y le halaga: le da muestras de afecto.

El quinto verbo, además de la partícula le anotada, lleva un complemento expreso: gobierna las obras. El hombre obedece aquí totalmente, y son suyas las obras, pero principalmente son obras de Cristo, que le orienta, le guía y le conduce.

$\mathrm{Y}$, finalmente, mejor, por todos estos motivos, el hombre, en tal estado, a semejanza del Apóstol, vive y no vive: No vive por sí, pero vive, porque en él vive Cristo y es la vida de su misma vida.

Hace preceder también, a cada uno de los verbos, la conjunción copulativa $y$, polisíndeton, recurso muy frecuente en Fray Luis, para expresar un matiz más: la profusión de bienes que acompañan al hombre y que Cristo distribuye continuamente en el alma en tal estado de gracia, para llevarla a la total felicidad.

De los que han llegado a tal estado dice Isaías ${ }^{131}$ :

Alegráronse con tu presencia, como la alegría en la siega; como se regocijaron al dividir el despojo.

Juliano comenta que habla de la alegría de la siega, porque en ella se coge "el fruto de lo trabajado y se conoce que la confianza... no salió vacía".

Es alegría grandísima la de los que llegan aquí, "porque comienzan a coger el fruto de su fe y penitencia, y ven que no les burló la esperanza, y sienten la largueza de Dios en sí mismos".

Tres cosas, continúa, llenan de alegría a los vencedores:

a) "El salir del peligro, b) el quedar con honra, c) el verse con tanta riqueza; porque (queda) vencido... todo lo que en el sentido hace guerra,... porque el Espíritu de Cristo nace y se derrama por él... (y) salen de peligro... (y) se hallan improvisamente dichosos y ricos" ${ }^{132}$.

131. Is $9,3(9,2)$ : Cita por la Vulgata.

132. BAC 738-739; AP 488. 
Juliano aduce como prueba el paso de Isaías ${ }^{133}$ :

Porque el yugo de la pesadumbre, y la vara de su hombro, y el cetro del ejecutor en él, lo quebraste como en el día de Madián.

$\mathrm{Y}$ explica misticamente que habla:

a) De yugo de pesadumbre, porque es carga que nos ata y nos oprime; b) de vara, porque con ella nos castiga el demonio; c) de su hombro, a semejanza de los verdugos antiguos, que traían al hombro las varas con que herían a los condenados; d) de cetro ejecutor, y en nosotros, porque por medio del hombre viejo ejecuta el enemigo su voluntad en nosotros.

Todo esto, concluye, Cristo lo quebranta cuando empieza a nacer en la carne.

\subsubsection{Aplicación mística del texto aducido}

Fray Luis aplica místicamente el texto aducido de Isaías a la actividad de Cristo en el alma, porque Cristo quebranta al anemigo "como en el día de Madián... alcanzó victorias Gedeón ${ }^{134}$ de los madianitas... con sólo quebrar los cántaros y resplandecer la luz que encerraban, y con tocar las trompetas".

En efecto, observa Juliano que el "comenzar Cristo a nacer en nosotros... es...obra de su misma virtud;... primero, como luz metida en medio del alma, se encierra allí y después se descubre y resplandece, quebrantando lo terreno y carnal del sentido. A cuyo resplandor, y al sonido que hace la voz de Cristo en el alma, huyen los enemigos y mueren. Y como en el sueño, que entonces vio uno,... un pan de cebada y cocido entre ceniza, que se revolvía por el campamento ${ }^{135}$ de los enemigos, (y) tocando las tiendas los derrocaba, así aquí Cristo, que es pan despreciado... y cocido en trabajos, revolviéndose por los sentidos del alma... los abrasa y consume" ${ }^{136}$.

Todo ello, añade, "lo purifica ${ }^{137}$ el santo fuego, que Cristo... dice ${ }^{138}$ que vino a poner en la tierra".

133. Is 9,4 (9,3): este paso, citado por Fray Luis, alude a la victoria de Gedeón, con sus trescientos, sobre los madianitas, narrada en el capítulo 7 de los Jueces.

134. Jue 7,9. El hecho aducido abarca, en realidad, todo el capítulo 7 de los Jueces, que ha de leerse completo para una cabal inteligencia, es decir: "Los trescientos hombres a que reduce Gedeón su ejército por mandato del Señor"; "el anuncio de la victoria"; "la estratagema de las trompetas y los cántaros vacíos"; "la persecución final a los madianitas".

135. "por el campamento": en el texto = "por el real".

136. BAC 739; AP 489-490.

137. "lo purifica": en el texto = "lo apura".

138. Lc 12,49 . 
Y, de nuevo, cita como prueba al profeta Isaías:

El pueblo de Sión habitará en Jerusalén. No llorará llorando; apiadándose se apiadará de ti. A la voz de tu grito, en oyéndola, te responderá. $Y$ daros ha el Señor pan estrecho y agua apretada. Y no volará más tu maestro; y... tus ojos le contemplarán; y tus orejas oirán a las espaldas tuyas palabras que te dirá: Éste es el camino, andad en él, no inclinéis a la derecha o a la izquier$d a^{139}$.

El paso citado de Isaías no puede ser más sugestivo. La presencia de Cristo, en efecto, impresiona los sentidos:

a) El oído: que al momento de oír su voz, responderá, porque oirá el susurro de las palabras del maestro.

b) El gusto, que sacia el pan (estrecho) y el agua (apretada).

c) La vista, que contemplará al maestro.

Fray Luis continúa interpretando místicamente el paso aducido de Isaías. Juliano observa, en efecto, que la vida de Cristo, "que vivía en el alcázar del alma, se extiende (ahora) por toda la cerca de ella... y la pacifica; y... hace ya su morada en la paz, y cesa el lloro... Y como vive ya Cristo en ellos, óyelos en llamando;... mejor,... lo que Él pide en ellos, eso es lo que piden; porque está en ellos su maestro metido,... no se les aparta ni se ausenta, y,... en hablando ellos, los oye... Y dales entonces Dios...el pan y el agua que dan vida verdadera, su cuerpo y su espíritu, que se derrama por ellos y los sustenta" ${ }^{140}$.

\section{5:6.4.2. Matiz ascético en la altura mística}

En esta misma altura mística, se aprecia, sin embargo, el matiz ascético, siempre necesario, en estos dones de Cristo en el alma. Por esto afirma que este pan se lo da Dios con brevedad y estrechez.

Aduce como prueba estos motivos:

1) "Lo uno, porque, de ordinario, mezcla Dios, con este pan que les da, adversidad y trabajos; 2) lo otro, porque es pan que sustenta en medio de los trabajos y de las apreturas del alma; 3) y lo último, porque en esta vida este pan vive como escondido, y como encogido en los justos" 141.

Termina con estas palabras del Apóstol ${ }^{142}$, que anuncian el tercer grado:

139. Is $30,19-21$.

140. "óyeles en llamando" = óyeles al momento que llaman.

141. BAC 740; AP 491.

142. Col 3, 3-4. 
Porque nuestra vida está escondida con Cristo en Dios; mas cuando Él apareciere, que es vuestra vida, entonces le pareceréis ${ }^{143}$ a Él en la gloria.

\subsection{Tercer grado: Estado final de gloria}

En el grado final: Estado de gloria, el alma llega a la plenitud del crecimiento en Cristo. Por esto concluye Juliano que entonces "acabará de crecer en los suyos Cristo perfectamente y del todo, cuando los resucitare del polvo inmortales y gloriosos, que será el grado tercero, y el último... Adonde su Espíritu y vida en Él se comunicará: 1) De lo alto del alma a la parte más baja de ella, 2) y de ella se extenderá por el cuerpo (de esta manera): a) quitando de él lo vicioso,... b) desterrando de él lo quebradizo y lo flaco, c) y vistiéndolo enteramente de sí" ${ }^{144}$.

\subsubsection{Idea cosmovisiva: Cristo, el centro de todo}

Presenta aquí una magnífica idea de cosmovisión:

En la mente de Fray Luis, Cristo aparece como el centro de la vida espiritual del hombre, como el motor del universo y el centro vital de la nueva humanidad, renovada por la fuerza del Espíritu de Jesús.

En este contexto teológico-místico pueden enmarcarse los Nombres de Cristo y podrían enmarcarse también las principales odas mayores de Fray Luis ${ }^{145}$.

En otras palabras:

Cristo, el Hijo de Dios, aparece aquí como el clásico Pantocrátor del arte antiguo, como el centro, el origen, el creador y el impulsor de la actividad y de la misma vida espiritual del hombre.

El Espíritu de Jesús, por tanto, promueve un cambio radical, una vida distinta, más elevada, que implica una nueva panorámica, una proyección nueva y unos principios nuevos, para una vida más elevada, centrada solamente en Cristo, más bien que el simple restablecimiento de un estado ya conocido.

143. "entonces le pareceréis" = "entonces apareceréis". La traducción del paso aducido parece un tanto confusa. Quedaría, tal vez, más claro así: "entonces también vosotros apareceréis con Él en la gloria". Esta sería una traducción más ceñida incluso a la misma Vulgata, que Fray Luis acostumbra seguir.

144. "vistiéndolo enteramente de sí": es decir, las obras son ya obras de Cristo mismo.

145. FRAY LUIS, por ejemplo: Vida retirada, Noche serena, etc. 


\subsubsection{Pensamiento afin en los Padres}

Pensamiento afín a éste de Fray Luis hallamos ya con alguna frecuencia en los Padres:

1. El Diálogo con Trifón de san Justino, nos habla del restablecimiento total de libres y esclavos por la fuerza de Cristo ${ }^{146}$.

2. La Carta a los Esmirniotas de san Ignacio de Antioquía, recuerda la unidad de Dios y de nosotros, en Cristo, "por la fuerza de la carne y sangre de Cristo" 147.

3. San Ireneo alude a "nueva humanidad en Dios, por medio de Cristo", en Contra las herejías ${ }^{148}$.

4. San Agustín, filósofo, y teólogo de la historia, afirma que la humanidad entera culmina con la venida de Cristo:

-En Contra Fausto maniqueo, por ejemplo, presenta a Cristo como el "centro y el quicio o el eje de toda la humanidad" 149.

-En las Confesiones, nos presenta a Cristo, como el único mediador posible y real, en medio de Dios y de los hombres, porque es igual a Dios por la divinidad e igual al hombre por la humanidad ${ }^{150}$.

-Y en De la Trinidad, especialmente en el libro cuarto del gran tratado, enseña que Cristo, hombre-Dios, es el único mediador de libertad y de vida, de unidad y salvación para todos los hombres ${ }^{151}$.

En los tiempos modernos, hallamos ampliada y actualizada esta misma idea en su sentido filosófico, teológico, y paleontológico incluso, en Teilhard de Chardin, quien presenta a Cristo como el "centro orgánico del universo, el alfa y omega, y como el motor de toda evolución y progreso" 152.

\subsubsection{Cristo, varón perfecto en los suyos}

El razonamiento que ha empleado Fray Luis por medio de Juliano, en todo su diálogo, $\mathrm{y}$, sobre todo, el que emplea en éste tercer grado o estado final de gloria, es totalmente coherente:

146. SAN Justino, Diálogo con Trifón, 134,4.

147. SAN IGNACIO DE ANTIOQUIA, Carta a los Esmirniotas, 12,2,

148. SAN IRENEO, Contra las herejías, 5,12,1.

149. SAN Agustin, Contra Fausto maniqueo, 13,11.

150. San Agustin, Confesiones, 10,42,67.

151. SAn Agustin, De la Trinidad, contexto principal del libro cuarto.

152. Teilhard De Chardin, contexto, por ejemplo, de Ciencia y Cristo, y de El medio divino. 
Del Espíritu de Cristo, en efecto, se extiende la vida divina al alma, del alma se extiende al cuerpo, quitando lo vicioso, desterrando de él lo quebradizo y lo flaco, y vistiéndolo totalmente de sí. Por esto, la vida y la actividad humana quedan totalmente invadidas por el Espíritu de Cristo, es decir: a) Todo su vivir, b) su querer, c) su entender, d) su parecer, e) su resplandecer será Cristo, que será entonces varón perfecto en todos los suyos, y será uno en todos, y todos serán hijos cabales de Dios, por tener en sí "el ser y el vivir" de este Hijo, que es único y solo Hijo de Dios, y es Hijo de Dios con todos los que se llaman sus hijos ${ }^{153}$.

\subsection{Conclusión de los cinco nacimientos}

Fray Luis deduce al final una conclusión general, muy de su estilo, a manera de corolario. Como es su costumbre, apoya en la Escritura la argumentación que ha hecho sobre los cinco nacimientos. Veamos:

Primer nacimiento: A Cristo, que nace del Padre en cuanto Verbo de Dios, la Escritura lo llama Yeled: el engendrado y sacado a luz.

Segundo nacimiento: A Cristo, nacido de María en cuanto hombre, lo llama Bar: el escogido, como el trigo limpio.

Tercer nacimiento: Al nacimiento de Cristo en la Resurrección, lo llama Nin: el que se va levantando para comenzar la nueva vida.

Cuarto nacimiento: A Cristo, que nace en la Eucaristía, lo llama Bar: el edificio.

Quinto nacimiento: A Cristo, que nace en el alma del justo por la gracia, lo llama Sil: el pacífico, el enviado.

Observa Fray Luis que todas estas cualidades los hebreos las aplicaron a los buenos hijos:

1) "El hijo es engendrado, 2) y criado y sacado a luz; 3) y es como lo apurado (depurado) y lo ahechado (lo limpio), como el grano de la criba, que sale del mezclarse los padres; 4) y el que se levanta en su lugar cuando ellos fallecen, sustentando su nombre; 5) y es como un edificio; por donde, aun en español, a los hijos y descendientes les damos el nombre de casa; 6) y es la paz el hijo, y como el nudo de concordia entre el padre y la madre" 154.

\subsection{Contemplación mística conclusiva de los cinco nacimientos}

Fray Luis aplica místicamente todos estos nombres, que se aplican de modo general a los hijos, a los cinco nacimientos de Cristo:

153. BAC 741; AP 491-492.

154. BAC 741; AP 492. 
1. Cristo, que nace como Verbo del Padre, "es el engendrado, según el nacimiento eterno" 155 .

2. Cristo, que nació de María Virgen, es "el sacado a luz, según el nacimiento de la carne, y lo apurado y ahechado de toda culpa según ella misma" ${ }^{156}$.

3. Cristo, que nació a nueva vida en la Resurrección, es "el que se levantó de los muertos" 157 .

4. Cristo, que nace en la Eucaristía, "es el edificio que encierra en la Hostia, donde se pone, a todos sus miembros" 158 .

5. Cristo, que nace en el alma de los justos, es "el que nace (por la gracia) en el centro de las almas, de donde envía poco a poco por todas sus partes de ellos la virtud de su Espíritu, que los apura (purifica) y aviva y pacifica y bastece (abastece) de todos sus bienes".

Y continúa con mayor hondura mística todavía:

"El es el Hijo de Dios, que sólo es Hijo de Dios en sí y en todos los demás que lo son ${ }^{159}$. Porque en Él se crearon, y por Él se reformaron ${ }^{160}$, y por... lo que de Él contienen en sí, son dichos sus hijos... Porque el Padre no tiene sino a Él solo por Hijo, ni ama como a hijos sino a los que en sí contiene y son una misma cosa con Él, un cuerpo, un alma un espíritu. Y así siempre ama a solo Él en todas las cosas que ama" ${ }^{161 .}$

Juliano terminó su larga disertación-diálogo y dijo:

"Hecho he, Sabino, lo que me pediste...; mas si os tengo cansado, por eso proveísteis bien que Marcelo sucediese luego, que con lo que dijere, nos descansará a todos" 162 .

Pero Marcelo, amablemente, dijo entonces, refiriéndose a Juliano:

"Yo fío ${ }^{163}$ que no le habéis cansado; más habéisme puesto en trabajo ${ }^{164}$ a mí, que después de vos, no sé qué decir que contente".

155. BAC 741-742; AP 493.

156. BAC 742; AP 493.

157. BAC id; AP id.

158. BAC id; AP id.

159. BAC id; AP id.

160. "crear y reformar" = SAN AGUSTIN emplea para esta misma idea las palabras "crear y re-recrear": Sobre el evangelio de San Juan, tr. 1,12. Respecto a esto, véase SERGio GonZALEZ, La preocupación arriana en la predicación de San Agustín, Estudio Agustiniano, Valladolid, 1989 p. 86, 5.

161. En realidad, el Padre ama solamente a su Hijo, y en Él a la creación entera, hecha por Él y para Él: Jn 1,3. Fue el plan de Dios al crear todas las cosas, especialmente al hombre = "Recapitular en Cristo todas las cosas del cielo y de la tierra": Ef 1,3-10.

162. BAC 742; AP 493.

163. "yo fío" = yo confío, aseguro.

164. "me habéis puesto en trabajo" = me habéis puesto en un compromiso, en apuros. 


\subsection{Episodio del avecilla}

El episodio incidental de una avecilla -de la pájara, que decía Sabino-, tiene dos partes:

Primera parte $=$ Incluye dos momentos distintos:

"Primer momento" = Persecución de los cuervos al avecilla:

Quería Sabino responder a Marcelo, mas estorbóselo un caso que sucedió:

"En la orilla contraria de donde Marcelo y sus compañeros estaban, en un árbol que en ella había, estuvo asentada una avecilla de plumas y de figura particular, cuasi ${ }^{165}$ todo el tiempo que Juliano decía ${ }^{166}$, como oyéndole, y a veces como respondiéndole con su canto... con tanta suavidad y armonía, que Marcelo y los demás habían puesto en ella los ojos y los oídos. Pues al punto que Juliano acabó, y Marcelo respondió,... y Sabino le quería replicar, sintieron ruido hacia aquella parte, y volviéndose ${ }^{167}$, vieron que lo hacían dos grandes cuervos que, revolando sobre el ave... y cercándola al derredor, procuraban hacerle daño con las uñas y los picos. Ella, al principio se defendía con las ramas del árbol, encubriéndose entre las más espesas. Mas... apretándola siempre más a doquiera que iba, forzada, se dejó caer en el agua, gritando y como pidiendo favor. Los cuervos acudieron también y, volando sobre la haz ${ }^{168}$ del río, la perseguían malamente, hasta que, a la fin, el ave se sumió toda en el agua, sin dejar rastro de sí" ${ }^{169}$.

"Segundo momento" = Tristeza de Sabino y sus compañeros:

"Aquí Sabino alzó la voz, y... dijo:

¡Oh, la pobre, y cómo se nos ahogó!"

$\mathrm{Y}$ así lo creyeron sus compañeros, de que mucho se lastimaron. Los enemigos, como victoriosos, se fueron alegres luego" 170 .

Segunda parte $=$ Comprende estos momentos:

"Primer momento" = La pájara sale ilesa del agua:

"Mas, como hubiese pasado un espacio de tiempo, y Juliano consolase a Sabino que... no podía perder ${ }^{171}$ la lástima de su pájara,... de improviso, a la parte donde Marcelo estaba, y casi junto a sus pies, la vieron sacar del agua la

165. "cuasi" = casi.

166. "decía" = hablaba. Fray Luis ha empleado ya esta palabra en el mismo sentido, por ejemplo, en Príncipe de Paz: BAC 646; AP 357.

167. "y, volviéndose, vieron" $=y$, mirando atentamente, vieron, porque ya la habían visto casi todo el tiempo en que Juliano hablaba.

168. "sobre la haz" = sobre la superficie: P. FELIX GARCIA, BAC 743, nota 213.

169. BAC 743; AP 494.

170. BAC id; AP id.

171. "no podía perder" = no podía apartar de sí, de su mente. 
cabeza, y luego salir del arroyo a la orilla, toda fatigosa y mojada. Como ${ }^{172}$ salió, se puso sobre una rama baja que estaba allí junto, adonde extendió sus alas, y las sacudió del agua; y después, batiéndolas con presteza, comenzó a levantarse por el aire, eantando con una dulzura nueva. Al canto, como llamadas otras muchas aves de su linaje, acudieron a ella de diferentes partes del soto. Cercábanla, y como dándole el parabién, le volaban al derredor. Y luego, juntas todas, y como en señal de triunfo, rodearon tres o cuatro veces el aire con vueltas alegres, y después se levantaron en alto poco a poco, hasta que se perdieron de vista".

"Segundo momento" = Comprende, a su vez, dos tiempos:

"Primer tiempo" = Alegría de Sabino:

"Fue grandísimo el regocijo y alegría que de este suceso recibió Sabino". "Segundo tiempo" = Misteriosa exclamación de Marcelo:

"Mas decíame ${ }^{173}$ que, mirando en este punto a Marcelo, le vio demudado en el rostro, y turbado algo, y metido ${ }^{174}$ en gran pensamiento, de que mucho se maravilló; y... viole que, levantando al cielo los ojos, como entre los dientes y con un suspiro disimulado, dijo:

-Al fin, Jesús es Jesús" ${ }^{175 .}$

\subsubsection{Paralelismo antitético entre las dos partes}

El paralelismo antitético entre las dos partes de la alegoría es sorprendente. Literariamente es insuperable.

Veamos:

Primera y segunda parte.

"Primer momento":

172. "como" = tan pronto como.

173. "mas decíame" = ¿a quién? Palabra de difícil interpretación. ¿Se refiere al autor, que oye esto a Sabino? Si admitimos los Nombres de Cristo como un diálogo humanístico, con influencias platónicas, aristotélicas, ciceronianas y patrísticas, además de la preparación y vivencia excepcional de Fray Luis, se explica que Marcelo, que hace sus veces, aparezca siempre como el más docto y como el más admirado y respetado por los otros dos dialogantes, porque es autor y personaje literario al mismo tiempo. Esta parece la explicación más sencilla.- Véase, respecto a esto, a CRISTOBAl Cuevas, Fray Luis de León, De los nombres de Cristo. Ed. Cátedra, Letras Hispanas, Madrid, 1986 III Libro, página 501, nota 20 y páginas 562-563, nota 179. Véanse también las opiniones del P. Felix Garcia, BAC 743, nota 216 y VAlentin SANChez Ruiz, AP 495, nota 1.

174. "y metido" = engolfado, ensimismado.

175. Al fin, Jesús es Jesús = Al fin, Jesús es Salvador. Fray Luis emplea un doble significado de la palabra Jesús: denominativo o apelativo, en el primer caso, y significativo, en el segundo. Es la consecuencia lógica del sentido metafórico que ha querido dar a la alegoría aducida anteriormente, y el peligro del que Jesús le ha "salvado": ver Mt 1,21; Hech 4,12; 13,23, etc. 
$\left.1^{a}\right)$ En la orilla contraria de los dialogantes, "en un árbol que en ella había, estuvo asentada una avecilla de plumas y figura particular, casi todo el tiempo que Juliano hablaba".

$2^{a}$ ) La avecilla "se puso sobre una rama baja".

$\left.1^{a}\right)$ La avecilla parecía "a veces como oyéndole, y a veces como respondiéndole con su canto; y esto con tanta suavidad y armonía, que Marcelo y los compañeros habían puesto en ella los ojos y los oídos".

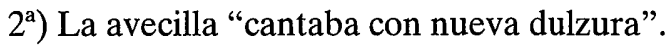

$\left.1^{a}\right)$ Los dialogantes "sintieron ruido;... y vieron que lo hacían dos grandes cuervos que, revolaban (revolando) sobre el ave y la cercaban (y cercándola) al derredor".

$2^{a}$ ) “...otras muchas aves de su linaje... cercábanla, y, como dándole el parabién, le volaban al derredor".

$\left.1^{a}\right)$ Los cuervos "procuraban hacerle daño con las uñas y con los picos... apretándola siempre más a doquiera que iba".

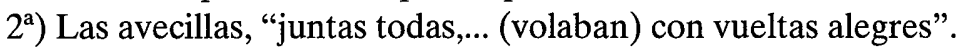

$\left.1^{a}\right)$ La avecilla, "forzada, se dejó caer en el agua, gritando y como pidiendo favor".

$2^{a}$ ) La avecilla "comenzó a levantarse por el aire".

$1^{\text {a }) ~ " L o s ~ c u e r v o s, . . . ~ v o l a n d o ~ s o b r e ~ l a ~ h a z ~ d e l ~ r i ́ o, ~ l a ~ p e r s e g u i ́ a n ~ m a l a m e n t e " . ~}$

$\left.2^{a}\right)$ Las aves, "rodearon tres o cuatro veces el aire con vueltas alegres".

$1^{\text {a) }}$ "Hasta que, al fin, (la avecilla) se sumió en el agua".

$2^{\mathrm{a}}$ ) "La vieron (al avecilla) sacar del agua la cabeza, y luego salir del arroyo a la orilla".

$\left.1^{a}\right)$ Los enemigos, "como victoriosos, se fueron alegres luego".

$2^{a}$ ) Las aves, "como en señal de triunfo, se levantaron en alto poco a poco, hasta que se perdieron de vista".

Primera y segunda parte.

"Segundo momento" = Reacción de Sabino y sus compañeros:

"Primer tiempo":

$1^{a}$ ) Grito angustioso de Sabino = "¡Oh, la pobre, y cómo se nos ahogó!” y lástima de sus compañeros por la suerte del avecilla.

$2^{a}$ ) "Fue grandísimo de regocijo y alegría que de este suceso recibió Sabino".

"Segundo tiempo":

"Mirando (Sabino) en este punto a Marcelo, le vio:

a) Demudado el rostro, b) y turbado algo, c) y metido en gran pensamiento...; d) y... viole que, levantando al cielo los ojos, como entre los dientes y con suspiro disimulado, dijo:

Al fin, Jesús es Jesús". 


\subsubsection{Simbolismo místico del paso de la avecilla}

El paso famoso de la avecilla tiene, sin duda, un carácter simbólico.

Posibles interpretaciones:

$\left.1^{\mathrm{a}}\right)$ ¿Persecuciones contra la Iglesia a través de toda su historia? $2^{\mathrm{a}}$ ) ¿Triunfo final, ineludible, por el poder de Cristo, de la inocencia perseguida? $3^{a}$ ) ¿Alusión a la "envidia y mentira" y a las persecuciones injustas contra Fray Luis, que lo llevaron, finalmente, a la cárcel? Esta última parece la hipótesis más segura, pero extensible a las dos primeras ${ }^{176}$.

Fácilmente puede deducirse del texto una referencia clara a Fray Luis, por las cualidades que le adornaban, de todos conocidas.

Referencias algóricas:

1) Fray Luis parece directamente simbolizado en la avecilla, la cual: a) Era "de plumas y de figura particular"; b) "cantaba con suavidad y armonía"; c) "forzada (por la persecución), se dejó caer en el agua, gritando y como pidiendo favor"; d) "hasta que, al fin, se sumió toda en el agua". e) Pasado un espacio de tiempo, sin embargo, fue a salir precisamente "a la parte donde estaba Marcelo, y casi junto a sus pies, la vieron sacar la cabeza, y luego salir del arroyo a la orilla". f) Y, al momento "que salió del agua, se puso junto a una rama que estaba allí junto"; g) "y... cantaba con nueva dulzura".

2) Los hermanos en religión y los amigos de Fray Luis, se hallan probablemente simbolizados en las otras muchas aves, las cuales, cuando la avecilla salió del agua:

a) "Cercábanla, b) y, como dándole el parabién, volaban al derredor". c) Y luego, juntas todas, y como en señal de triunfo, rodearon tres o cuatro veces el aire con vueltas alegres; d) "y después se levantaron poco a poco, hasta que se perdieron de vista".

3) Los enemigos de Fray Luis, finalmente, se hallan, tal vez, alegorizados en los dos grandes cuervos, los cuales:

a) "Revolaban sobre la ave,... b) y cercándola al derredor, procuraban hacerle daño... c) apretándola siempre más a doquiera que iba" d) Y, finalmente, "como victoriosos, se fueron alegres".

4) La misteriosa exclamación o invocación final:

Al fin, Jesús es Jesús = Al fin, Jesús es Salvador, trascendentaliza, pues, los límites de la experiencia personal de Fray Luis, para que este hecho sirva

176. En esta tercera hipótesis: a) La avecilla, indefensa materialmente, pero inocente, simbolizaría al propio Fray Luis; b) los dos cuervos, de fuertes picos y uñas afiladas, representarían a sus dos mayores enemigos: Bartolomé Medina y León de Castro; c) las aves, que corean a la avecilla, milagrosamente salvada del agua, significarían a sus hermanos en religión y a sus amigos. 
de esperanza en Jesús a cuantos se hallen injustamente perseguidos en el futuro ${ }^{177}$ por "la envidia y la mentira" o por cualquier otra injusticia de los hombres.

Es indudable, por lo tanto, que la alegoría de la avecilla se refiere a la experiencia histórica personal, vivida por Fray Luis, pero con una proyeción mística de carácter universal.

SERgio GonZÁleZ

177. Presentado de esta manera el simbolismo, no tiene sentido citar nombre alguno: en primer lugar, por razones de elemental prudencia, y, sobre todo, por la proyección universal que Fray Luis quiere dar a la alegoría del avecilla. 